\title{
Links between Rossby Wave Breaking and the North Atlantic Oscillation-Arctic Oscillation in Present-Day and Last Glacial Maximum Climate Simulations
}

\author{
GWENDAL RIVIÈRE \\ CNRM/GAME, Météo-France/CNRS, Toulouse, France \\ ALEXANDRE LAÎNÉ AND GuILLAUME LAPEYRE \\ LMD/IPSL, ENS/CNRS, Paris, France \\ DAVID SALAS-MÉLIA \\ CNRM/GAME, Météo-France/CNRS, Toulouse, France \\ MASA KAGEYAMA \\ LSCE/IPSL, UMR CEA-CNRS-UVSQ 8212, Gif-sur-Yvette, France
}

(Manuscript received 6 August 2009, in final form 15 January 2010)

\begin{abstract}
Upper-tropospheric Rossby wave-breaking processes are examined in coupled ocean-atmosphere simulations of the Last Glacial Maximum (LGM) and of the modern era. LGM statistics of the Northern Hemisphere in winter, computed from the Paleoclimate Modeling Intercomparison Project Phase II (PMIP2) dataset, are compared with those from preindustrial simulations and from the 40-yr ECMWF Re-Analysis (ERA-40). Particular attention is given to the role of wave-breaking events in the North Atlantic Oscillation (NAO) for each simulation. Anticyclonic (AWB) and cyclonic (CWB) wave-breaking events during LGM are shown to be less and more frequent, respectively, than in the preindustrial climate, especially in the Pacific. This is consistent with the slight equatorward shift of the eddy-driven jets in the LGM runs. The most remarkable feature of the simulated LGM climate is that it presents much weaker latitudinal fluctuations of the eddy-driven jets. This is accompanied by less dispersion in the wave-breaking events. A physical interpretation is provided in terms of the fluctuations of the low-level baroclinicity at the entrance of the storm tracks. The NAO in the preindustrial simulations and in ERA-40 is characterized by strong latitudinal fluctuations of the Atlantic eddy-driven jet as well as by significant changes in the nature of the wave breaking. During the positive phase, the eddy-driven jet moves to the north with more AWB events than usual and is well separated from the subtropical African jet. The negative phase exhibits a more equatorward Atlantic jet and more CWB events. In contrast, the LGM NAO is less well marked by the latitudinal vacillation of the Atlantic jet and for some models this property disappears entirely. The LGM NAO corresponds more to acceleration-deceleration or extension-retraction of the Atlantic jet. The hemispheric point of view of the Arctic Oscillation exhibits similar changes.
\end{abstract}

\section{Introduction}

The Last Glacial Maximum (LGM; $21000 \mathrm{yr}$ ago) is one of the most modeled climates of the past. In particular, it serves as a basis to estimate the ability of the models to simulate a very different climate from the present one. During the last decade, significant improvements have

Corresponding author address: Gwendal Rivière, Météo-France, CNRM/GMAP/RECYF, 42 av. G. Coriolis, 31057 Toulouse CEDEX 1, France.

E-mail: gwendal.riviere@meteo.fr been achieved, especially through the Paleoclimate Modeling Intercomparison Project (PMIP) in which different models have been run with common boundary conditions characterizing a given paleoclimate (either LGM or midHolocene). An important step was made from the first phase of PMIP (PMIP1; Joussaume and Taylor 1995) for which sea surface temperatures (SSTs) were prescribed or given from a simple slab ocean, to the second phase of PMIP (PMIP2; Braconnot et al. 2007) in which fully coupled ocean-atmosphere simulations have been performed. 
Because of the decrease in atmospheric greenhouse gases, the presence of large ice sheets, such as the Laurentide over North America, and the consistent differences in SST distributions compared to the present climate, a significant change in the low-level tropospheric temperature gradient and in the baroclinicity is expected for the LGM. Because baroclinicity is a crucial factor determining the behavior of midlatitude cyclogenesis, drastic differences are also expected in stormtrack dynamics between the two climates. In a systematic study of the PMIP1 models, Kageyama et al. (1999b) have presented evidence of a northeastward extension of both the Northern Hemisphere storm tracks and the extratropical jets. However, these characteristics were forced, for a large part, by the extreme conditions of the Climate: Long-range Investigation, Mapping, and Prediction (CLIMAP) SST reconstructions, characterized by sea ice covering the North Atlantic Ocean north of $45^{\circ} \mathrm{N}$. In the PMIP2 coupled ocean-atmosphere model results, sea ice is much less extensive and storm tracks exhibit a more southeastward extension, especially in the Pacific, as shown by Laîné et al. (2009, hereafter L09), and jets are more zonally oriented (Li and Battisti 2008). Another remarkable feature of the PMIP2 simulations concerns the activity of the storm tracks. Despite an increase of the baroclinicity, particularly at the entrance of the Atlantic storm track, the intensity of the storms is not systematically greater in PMIP2 simulations of LGM, with some models even leading to a reduced Atlantic storminess. This property is similar to the midwinter suppression of the Pacific storm-track activity observed by Nakamura (1992) and Chang (2001). The following two properties may explain this behavior: first, storms are less efficient at extracting energy from their environment, as shown by L09, and second, the seeding is weaker at the entrance of the Atlantic storm track, as underlined by Donohoe and Battisti (2009).

Storm-track dynamics at LGM is therefore the subject of recent active research. However, its feedback onto the large-scale atmospheric circulation has only been analyzed in a very few studies (Justino et al. 2005) and constitutes the main subject of the present paper. A relatively new approach to study this aspect is to consider Rossby wave-breaking events in the upper troposphere that make possible the transfer of energy from the high- to the lowfrequency parts of the flow. During their breaking, waves are able to accelerate the large-scale jets or even to displace them at different latitudes in few days (Rivière and Orlanski 2007). Baroclinic waves may typically break in two different ways (Thorncroft et al. 1993): one is anticyclonic wave breaking (AWB), which is related to a southwest-northeast orientation of the waves, and the other is cyclonic wave breaking (CWB), which is accompanied by a northwest-southeast tilt. The former tends to push the jet poleward and the latter pushes equatorward. This can be easily deduced from classical diagnostics, such as the eddy momentum fluxes or the $\mathbf{E}$ vector introduced by Hoskins et al. (1983). During AWB events, momentum fluxes are poleward, leading to a convergence of the fluxes poleward and a divergence equatorward of the jet, accelerating and decelerating this jet poleward and equatorward, respectively. The reverse is valid for CWB. L09 have shown (see their Fig. 6) evidence of more equatorward momentum fluxes during LGM in comparison with the present climate in four different PMIP2 models. This suggests a tendency toward more CWB and less AWB, which will be confirmed in the present study. However, neither the $\mathbf{E}$ vector nor the eddy momentum fluxes provide exactly the same information as wave breaking: for example, anomalies of eddy momentum fluxes may occur without a significant signature in wave breaking because the waves are not strong enough to locally reverse the mean westerlies. Performing wave-breaking analyses in climate simulations therefore complete the information given by more classical tools.

Using a global primitive equation model of the atmosphere, Akahori and Yoden (1997) have observed a close relationship between the latitudinal fluctuations of the zonal wind and the two types of wave-breaking events. AWB is more frequent during the period of a high-latitude jet while CWB happens more often for a low-latitude jet. These two phenomena are closely interwoven. As discussed above, AWB (CWB) favors more the appearance of a high-latitude (low latitude) jet. However, the reverse is also true, as shown by Rivière (2009, hereafter R09), due to potential vorticity gradient asymmetries related to the variations of the Coriolis parameter: a high-latitude (low latitude) jet will induce more AWB (CWB) events. The link between the two phenomena will be analyzed in the PMIP2 LGM and preindustrial simulations and compared to the 40-yr European Centre for Medium-Range Weather Forecasts (ECMWF) ReAnalysis (ERA-40) data (Uppala et al. 2005).

Recent studies based on the present climate have proved the dynamical link connecting the different kinds of Rossby wave-breaking events to the low-frequency variability of the troposphere, such as the North Atlantic Oscillation (NAO; e.g., Benedict et al. 2004; Rivière and Orlanski 2007; Martius et al. 2007; Strong and Magnusdottir 2008; Woollings et al. 2008). Despite some nuances among these studies, the main result is that the negative and positive phases of the NAO, respectively related to a more southward and northward position of the eddy-driven Atlantic jet, exhibit more CWB and AWB than on the long-term average, respectively. The aim of 
our study is not only to investigate the nature of Rossby upper-tropospheric wave-breaking processes at the LGM in comparison with the present climate, but also to use this approach to better understand the extratropical lowfrequency atmospheric variability such as the Arctic Oscillation (AO) or NAO at the LGM.

Most of the LGM numerical studies have focused on the climatological means of the atmospheric circulation and the storm tracks, but much less on their variability. Kageyama et al. (1999a) have noticed a severe change in low-frequency dynamics at LGM in an atmospheric general circulation model. Very different weather regimes compared to the present climate were identified and characterized by an eastward shift of their centers of action. Using a coupled atmosphere-ocean-sea ice model, Justino and Peltier (2005) have found a glacial NAO with four distinct centers of action but did not make a link with eddy-driven jet properties.

In the present study, a systematic analysis of the LGM and preindustrial runs of four PMIP2 models is performed as well as an intercomparison with the ERA-40 data. For each model, the link between the different phases of the NAO/AO, the eddy-driven jet properties, and the nature of the wave-breaking events will be shown and interpreted. Section 2 presents the properties of the models as well as the reanalysis dataset used in the study. The wave-breaking detection algorithm based on the reversal of the absolute vorticity gradient is described in section 3. Section 4 is dedicated to all of the results, including the frequency of occurrence of wavebreaking events for the different datasets and their link with the latitudinal fluctuations of the zonal wind and the NAO/AO. Finally, a conclusion is provided in section 5.

\section{Models and reanalysis data}

The PMIP2 fully coupled atmosphere-ocean general circulation models used in the present study are L'Institut Pierre-Simon Laplace Coupled Model, version 4 (IPSL CM4), Centre National de Recherches Météorologiques Coupled Global Climate Model, version 3.3 (CNRMCM3.3), Model for Interdisciplinary Research on Climate 3.2 (MIROC3.2), and third climate configuration of the Met Office Unified Model (HadCM3), for which the daily data needed for our analysis were available. These four models and their corresponding runs are the same as those analyzed in L09, except for CNRM-CM3.3, which is a new version of the CNRM model. Two types of runs are systematically compared for each model-one corresponds to LGM conditions and the other to preindustrial conditions (PREIND). The LGM conditions essentially differ from the modern ones in the greenhouse gas (GHG) concentrations, in ice sheet and coastlines
TABLE 1. Characteristics of the models used in the study.

\begin{tabular}{lcc}
\hline \hline \multicolumn{1}{c}{ Models } & $\begin{array}{c}\text { Atmospheric horizontal } \\
\text { grid }(\text { lat } \times \text { lon })\end{array}$ & $\begin{array}{c}\text { Atmospheric vertical } \\
\text { resolution }\end{array}$ \\
\hline IPSL CM4 & $72 \times 96$ & 19 \\
CNRM-CM3.3 & $64 \times 128$ & 31 \\
MIROC3.2 & $64 \times 128$ & 20 \\
HadCM3 & $72 \times 96$ & 19 \\
\hline
\end{tabular}

properties, and in the orbital parameters [PMIP2 boundary conditions; see Braconnot et al. (2007), and information online at http://pmip2.lsce.ipsl.fr]. GHG concentrations for the LGM (185 ppm for $\mathrm{CO}_{2}, 350 \mathrm{ppb}$ for $\mathrm{CH}_{4}$, and $200 \mathrm{ppb}$ for $\mathrm{N}_{2} \mathrm{O}$ ) are lower than in the preindustrial climate (280 ppm for $\mathrm{CO}_{2}, 760 \mathrm{ppb}$ for $\mathrm{CH}_{4}$, and $270 \mathrm{ppb}$ for $\mathrm{N}_{2} \mathrm{O}$ ). The presence of large ice sheets in the Northern Hemisphere is the most distinguishable feature of the LGM climate compared to the preindustrial climate and affects not only the albedo but also the topography. The PMIP2 ice sheet conditions are based on the ICE-5G reconstructions of Peltier (2004) and significantly differ from the ICE-4G reconstructions (Peltier 1994), which were used in the PMIP1 simulations. One particular difference for our topic of analysis is the higher topography of the Laurentide Ice Sheet in ICE-5G than in ICE-4G (Kageyama et al. 2006; Justino et al. 2006).

The characteristics of the models are summarized in Table 1 . From each simulation, daily data of 20 consecutive years have been extracted, and only the DecemberFebruary (DJF) period in the Northern Hemisphere is taken into account.

It has been checked with IPSL CM4 and CNRM-CM3.3 that the present climate simulations (i.e., the climate of the midtwentieth century) are not significantly different from preindustrial runs in terms of wave-breaking processes and eddy-driven jet properties. This renders possible the comparison between preindustrial runs and the ERA-40 (Uppala et al. 2005). The daily ERA-40 dataset used in the present study spans all of the DJF periods from 1957 to 2002 . The fields are interpolated on a longitudelatitude grid with a $2.5^{\circ}$ horizontal resolution.

\section{Wave-breaking detection method}

The wave-breaking detection method is the same as that described and used in R09. The purpose of the algorithm is to detect at each date all of the regions where there is a local reversal of the absolute vorticity gradient at $200 \mathrm{hPa}$. A more adequate diagnostic would be the reversal of the potential-vorticity gradient on an isentropic surface, but the latter cannot be obtained by the output variables of the PMIP2 runs. The absolute vorticity 
a. CWB

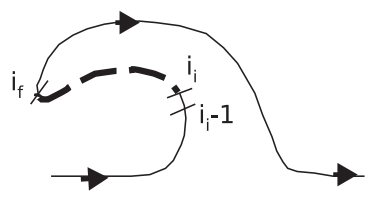

W b. AWB

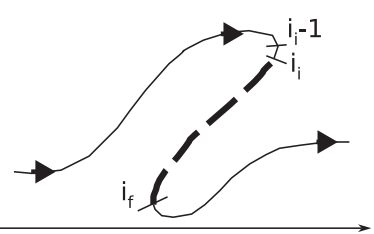

E

FIG. 1. Schematic describing the wave-breaking detection method. Each contour represents an isoline of absolute vorticity on an isobaric surface and is oriented from west to east. The thin part of the contour corresponds locally to a south-north oriented gradient of absolute vorticity, while the dashed heavy part corresponds to a north-south orientation, and hence to a local reversal of the absolute vorticity gradient. The latter part defines a wave-breaking region. When the first point $i_{i}$ along the wave-breaking region is more to the north (south) than the previous one $i_{i}-1$ along the contour, all of the points from $i_{i}$ to $i_{f}$ belonging to the dashed heavy part of the contour are considered to be related to a CWB (AWB) event. More details are given in the text.

is easily computed from the horizontal wind components. At a given isobaric level, we consider each circumpolar contour of absolute vorticity corresponding to a multiple of $2 \times 10^{-5} \mathrm{~s}^{-1}$. The choice of the circumpolar contours (similarly to Strong and Magnusdottir 2008) is to avoid detection of isolated patches of high or low vorticity that are not related to the wave-breaking process itself. All of the contours defined by the longitudes and latitudes $\{[\lambda(i), \varphi(i)], 1 \leq i \leq N\}$ are ordered from west to east (with $i$ being the increment of the contour); that is, we impose $\lambda(1)<\lambda(N)$. All segments $\left\{[\lambda(i), \varphi(i)], i_{i} \leq i \leq i_{f}\right\}$ along a contour presenting a local westward orientation, that is, satisfying $\lambda(i+1)<\lambda(i)<\lambda(i-1)$ for each $i \in\left(i_{i}, i_{f}\right)$, are considered as belonging to a wave-breaking region. Then, if the two first points along the segment are oriented northwestward (southwestward), then the entire segment is considered a CWB (AWB) case; that is, if $\varphi\left(i_{i}-1\right) \leq \varphi\left(i_{i}\right)\left[\varphi\left(i_{i}-1\right) \geq \varphi\left(i_{i}\right)\right]$. Figure 1 illustrates these two cases.

The next step of the algorithm is to determine the presence of wave breaking and its nature on each point of the initial grid. To do so, at each day $t$, we define two wave-breaking event functions on the initial grid, $\beta_{c}(\lambda$, $\varphi, t)$ and $\beta_{a}(\lambda, \varphi, t)$, as follows. Initially these functions are set to zero; then, for all of the points belonging to the previously defined segments, we determine their closest point $(\lambda, \varphi)$ over the initial gridpoint space. If the segment is a CWB case, then $\beta_{c}(\lambda, \varphi, t)=1$; if it is an AWB case, then $\beta_{a}(\lambda, \varphi, t)=1$. If $\beta_{i}(\lambda, \varphi, t)=1$ during six consecutive days at the same grid point, then $\beta_{i}$ is set to zero for all of these days in order to avoid detection of absolute vorticity gradient reversal that is not related to

transient waves. The next step consists in time averaging $\beta_{c}(\lambda, \varphi, t)$ and $\beta_{a}(\lambda, \varphi, t)$ over a given period to get the frequencies of occurrence of CWB and AWB events. In what follows, the time averages of $\beta_{c}(\lambda, \varphi, t)$ and $\beta_{a}(\lambda, \varphi, t)$ are denoted as $\gamma_{c}(\lambda, \varphi)$ and $\gamma_{a}(\lambda, \varphi)$, respectively. They correspond to climatological means (e.g., Fig. 2) or to monthly averages (e.g., Figs. 4-5), depending on the figures.

\section{Results}

\section{a. Climatology and month-to-month variability of zonal winds and wave-breaking events}

\section{1) ZONAL WINDS}

The winter climatology of zonal winds is displayed in Fig. 2. The main characteristics of the ERA-40 zonal winds (Fig. 2a), such as the strong and zonally oriented Pacific jet and the weaker Atlantic jet, are also present in the PREIND simulations (first column of Fig. 2). However, discrepancies exist as well; models have difficulties in reproducing the double-jet structure in the eastern Atlantic and the southwest-northeast orientation of the Atlantic midlatitude jet. This is especially the case for CNRM-CM3.3 (Fig. 2d) and HadCM3 (Fig. 2h). Zonalwind maxima in LGM (second column of Fig. 2) are stronger than in PREIND, especially in the Atlantic. In terms of latitudinal variations, the jets do not change their mean position significantly. For some models, the zonal-wind difference between PREIND and LGM is even weaker than the difference between PREIND and ERA-40. This suggests that the mean position of the jets provided by the LGM simulations should be taken with caution.

There is a slight but robust distinct feature between LGM and PREIND that consists of a reduction of the westerlies on the north side of the jets in LGM relative to PREIND. A general southward displacement of the northernmost $10 \mathrm{~m} \mathrm{~s}^{-1}$ contour at $200 \mathrm{hPa}$ from PREIND to LGM can be observed in both the Pacific and Atlantic for all models, except for CNRM-CM3.3 in the Atlantic sector (Fig. 2). The same tendency appears for the zonal wind at $500 \mathrm{hPa}$ on Fig. 3. In the regions where the northernmost $10 \mathrm{~m} \mathrm{~s}^{-1}$ contour is shifted from PREIND to LGM, it is systematically southward. It is particularly obvious in the eastern Atlantic for IPSL CM4 (Fig. 3a), CNRM-CM3.3 (Fig. 3b), and HadCM3 (Fig. 3d), and in the eastern Pacific for MIROC3.2 (Fig. 3c), even though in other regions the shift is small or even missing. A dynamical explanation for this reduction of the westerlies on the northern side of the jets is provided in the next two sections in terms of Rossby wave breaking. 


\section{a. ERA40}

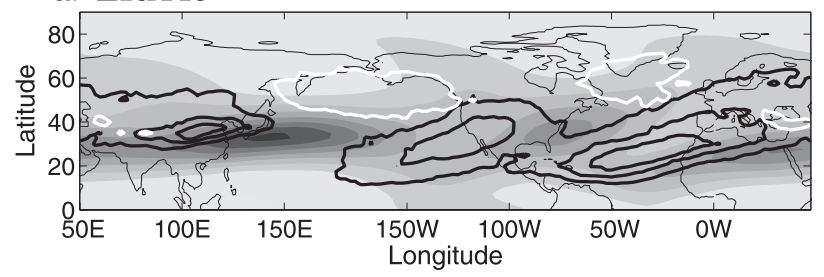

b. IPSL, Pre-ind

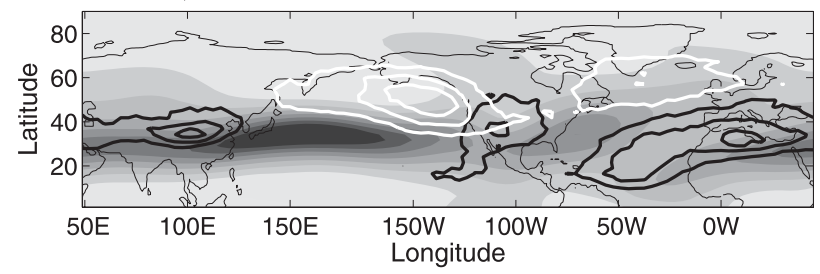

d. CNRM, Pre-ind

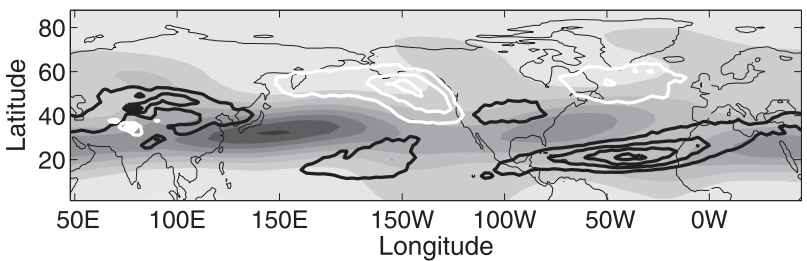

f. MIROC, Pre-ind

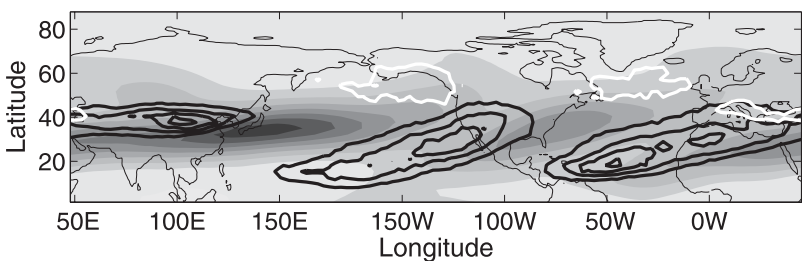

h. HadCM3, Pre-ind

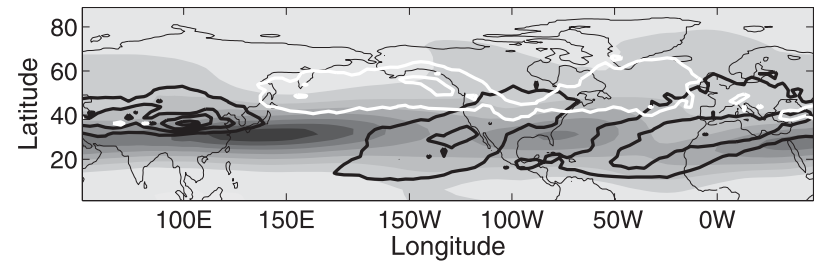

c. IPSL, LGM

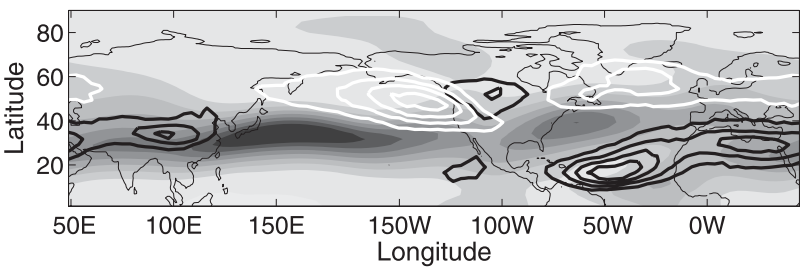

e. CNRM, LGM

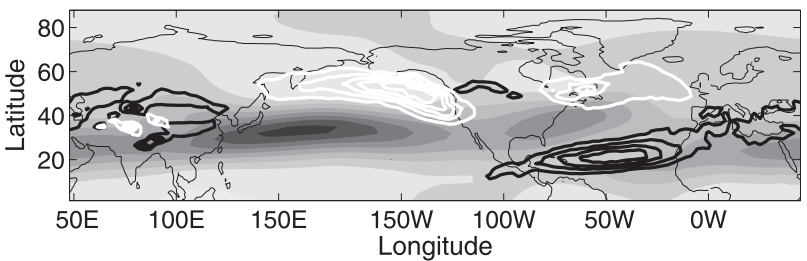

g. MIROC, LGM

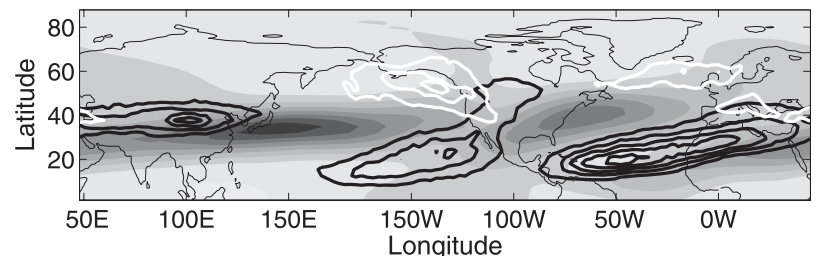

i. HadCM3, LGM

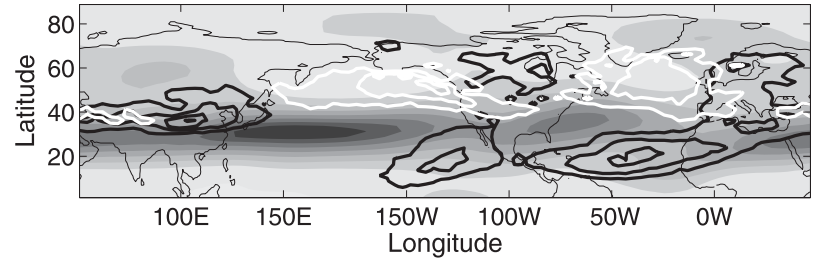

FIG. 2. Winter climatology of frequency of occurrence of AWB ( $\gamma_{a}$, black contours) and CWB ( $\gamma_{c}$, white contours) events at 200 hPa in (a) ERA-40, and (left) preindustrial and (right) LGM simulations (contour interval of 0.05 day $^{-1}$ ). Shaded areas represent the zonal wind at $200 \mathrm{hPa}$ (interval of $10 \mathrm{~m} \mathrm{~s}^{-1}$ ). (b),(c) IPSL CM4, (d),(e) CNRM-CM3.3, (f),(g) MIROC3.2, and (h),(i) HadCM3 are shown.

\section{2) FREQUENCY OF OCCURRENCE OF WAVE-BREAKING EVENTS}

In all cases, the AWB and CWB events occur more frequently at the end of the Pacific and Atlantic storm tracks (see panels of Fig. 2). Usually $\gamma_{c}$ and $\gamma_{a}$ have two peaks corresponding to the two storm tracks in all simulations, but with various amplitudes; $\gamma_{a}$ presents another important peak over the Himalayas, which will not be considered in the present study because it is not related to storm-track dynamics. Both $\gamma_{c}$ and $\gamma_{a}$ in the
ERA-40 data (Fig. 2a) closely resemble the equivalent densities computed by Strong and Magnusdottir (2008) by applying their own wave-breaking detection method to the National Centers for Environmental PredictionNational Center for Atmospheric Research (NCEPNCAR) reanalysis (see their Fig. 2). Much more AWB and slightly less CWB are present in the Atlantic compared to the Pacific. This may explain in part why the eddy-driven Atlantic jet moves more to the north at the end of the storm track than the Pacific jet, and why the former gets a southwest-northeast orientation and 

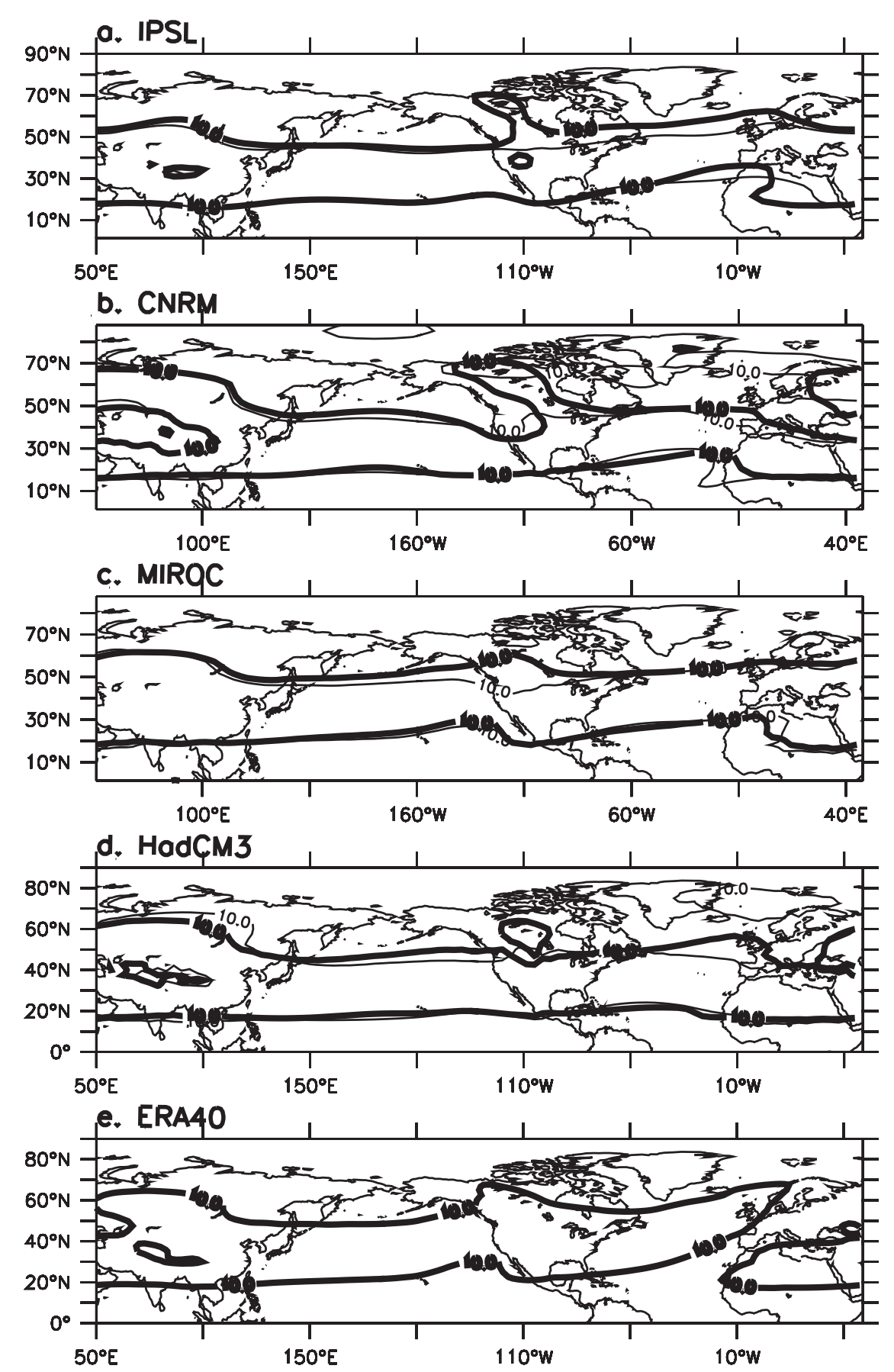

FIG. 3. Zonal wind at $500 \mathrm{hPa}$ (contour $10 \mathrm{~m} \mathrm{~s}^{-1}$ only) in LGM (thin contours) and preindustrial (thick contours) simulations. (a) IPSL CM4, (b) CNRM-CM3.3, (c) MIROC3.2, (d) HadCM3, and (e) ERA-40.

the latter a more zonal orientation. Indeed, when AWB dominates largely over CWB in a given storm track, the associated eddy-driven jet is shifted more poleward as wave-breaking events become more intense in the region of maximum eddy activity or slightly downstream from it. The jet that extends from the beginning to the end of the storm track therefore gets a southwestnortheast orientation (see R09 for more details).

The PREIND runs in the Pacific as well as in the Atlantic generally shows a deficit of AWB events compared to ERA-40. This difference is particularly true in the Atlantic where the mean of $\gamma_{a}$ is equal to $0.073 \mathrm{day}^{-1}$ for 
ERA-40 data, while the equivalent diagnostics are 0.055 , 0.046, 0.059, and $0.062 \mathrm{day}^{-1}$ for PREIND runs of IPSL CM4, CNRM-CM3.3, MIROC3.2, and HadCM3, respectively. This may partly explain why models tend to create a more zonally oriented Atlantic jet and have difficulties in reproducing the southwest-northeast tilt of the observed Atlantic jet.

L09 have underlined a large difference in the pattern of the high-frequency eddy momentum fluxes between preindustrial and LGM runs. The southward and northward fluxes tend to increase and decrease in amplitude, respectively, from PREIND to LGM. During CWB, the northwest-southeast orientation of the waves essentially creates southward fluxes, while AWB is more characterized by the reverse tilt and poleward fluxes. This result suggests that more CWB and less AWB should occur at LGM than in the present climate, which is confirmed by $\gamma_{a}$ and $\gamma_{c}$ shown on Fig. 2.

In the LGM, $\gamma_{c}$ (see white contours on Fig. 2) is usually higher than in PREIND in both storm tracks, except for the CNRM-CM3.3 and MIROC3.2 over the Atlantic where the differences are not clear. Over the Pacific, this increase in frequency of CWB events is accompanied by a decrease of AWB events at LGM. Over the Atlantic, the result is complex. For example, in the IPSL CM4 and HadCM3 runs, the maximum values of $\gamma_{a}$ over the Atlantic are reached at the LGM, but the region spanned by values greater than $0.05 \mathrm{day}^{-1}$ is narrower at the LGM.

Further insight on wave-breaking properties can be gained by spatially averaging the difference between the two wave-breaking densities $\gamma_{a}-\gamma_{c}$ over each oceanic basin as shown on Fig. 4 for the Pacific and on Fig. 5 for the Atlantic. Each point in each panel of these figures corresponds to spatial averages of $\gamma_{a}-\gamma_{c}$, themselves computed as the time averages of $\beta_{a}-\beta_{c}$ over one particular winter month. The general tendency toward more CWB and less AWB at the LGM over the Pacific is confirmed by analyzing the displacement of the points from PREIND to LGM along the $x$ axis. It is particularly obvious for CNRM-CM3.3 (Figs. 4d,e), MIROC3.2 (Figs. 4f,g), and HadCM3 (Figs. 4h,i), while for IPSL CM4 (Figs. 4b,c) the average of $\gamma_{a}-\gamma_{c}$ does not significantly change over the Pacific. There is also a systematic decrease of the standard deviation of $\gamma_{a}-\gamma_{c}$ from PREIND to the LGM in all of the models, which means a smaller variability of wave-breaking events in the LGM climate in the Pacific (see their values in each panel). This change in the dispersion is most drastic for the CNRM-CM3.3 case (Figs. 4d,e).

In contrast to the Pacific, differences between the LGM and PREIND are less consistent in the Atlantic (Fig. 5), as already suggested by Fig. 2. The spatial and temporal means of $\gamma_{a}-\gamma_{c}$ do not change so much from PREIND to LGM in IPSL CM4 and CNRM-CM3.3 (Figs. 5b-e). For IPSL CM4 (Figs. 5b,c), there is a slight decrease of the spatial means of both $\gamma_{a}$ and $\gamma_{c}$ from PREIND to LGM (not shown), while Figs. 2b,c show that the maximum of $\gamma_{a}$ is stronger in the LGM. This apparent contradiction means that the densities are much more localized in the LGM than in PREIND. Wavebreaking events occur more or less always in the same regions in the LGM, whereas they cover a larger area in PREIND. For MIROC3.2 (Figs. 5f,g), the tendency in the Atlantic is rather the opposite of what happens in the Pacific because $\gamma_{a}-\gamma_{c}$ reaches higher values in the LGM (Figs. 2f,g). In contrast, for HadCM3, results in the Atlantic are similar to the Pacific with a significant decrease of $\gamma_{a}-\gamma_{c}$ from PREIND to LGM (Figs. 5h,i). The latter model is the most sensitive one over this region because the spatial and temporal means of $\gamma_{a}-\gamma_{c}$ in PREIND is twice the value reached in the LGM, while this change is less than $20 \%$ of that for other models.

\section{3) THE LiNK BETWEen LATITUdinAL FLUCTUATIONS OF THE ZONAL WIND AND WAVE-BREAKING EVENTS}

The latitude of the eddy-driven jet is represented as a function of the difference between the two wavebreaking densities $\gamma_{a}-\gamma_{c}$ at $200 \mathrm{hPa}$ on Figs. 4-5. The latitude of the eddy-driven jet is estimated by the latitude of the maximum of the zonally averaged zonal wind at $500 \mathrm{hPa}$. Each zonal average is computed over a longitudinal band covering a storm-track region: $150^{\circ} \mathrm{E}-$ $110^{\circ} \mathrm{W}$ for the Pacific and $80^{\circ} \mathrm{W}-10^{\circ} \mathrm{E}$ for the Atlantic. The choice of the $500-\mathrm{hPa}$ level, and not $200 \mathrm{hPa}$, is to avoid detection of the subtropical jet. This distinction is particularly important when the eddy-driven jet is well separated from the subtropical jet, as is the case during the positive phase of the NAO (Vallis and Gerber 2008). This can easily be made by the choice of the vertical level because the subtropical jet is characterized by strong winds in the upper troposphere decreasing rapidly at lower levels while the eddy-driven jet has a much stronger barotropic component. The maximum zonal wind at $500 \mathrm{hPa}$ therefore detects the eddy-driven jet more systematically rather than the subtropical jet. It has been checked that the following results are very similar if the chosen level is $850 \mathrm{hPa}$ (not shown).

All of the results present a positive correlation between the jet latitude and $\gamma_{a}-\gamma_{c}$, with values ranging from 0.4 to 0.8 . For example, using ERA-40 data, the correlation is 0.72 in the Pacific and 0.48 in the Atlantic. A remarkable feature appearing in the PMIP2 results shown on Figs. 4-5 concerns the difference between LGM and PREIND. Latitudinal fluctuations of the eddy-driven 


\section{b. IPSL, Pre-ind}

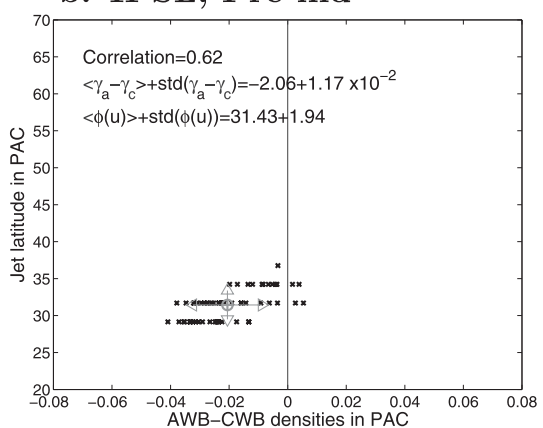

d. CNRM, Pre-ind

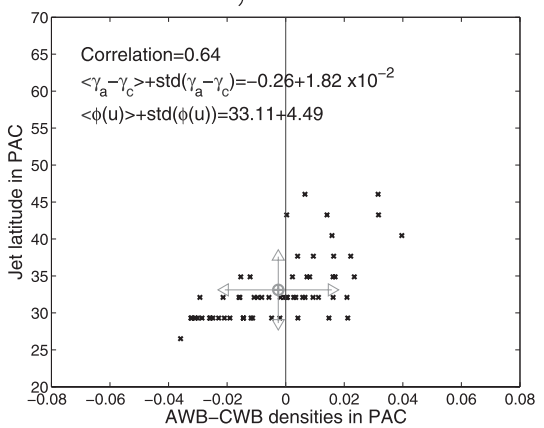

f. MIROC, Pre-ind

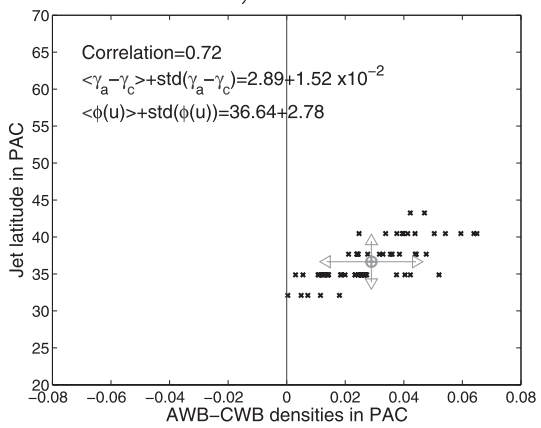

h. HadCM3, Pre-ind

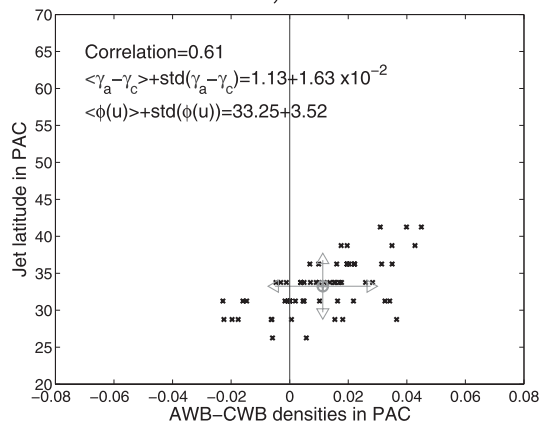

\section{c. IPSL, LGM}

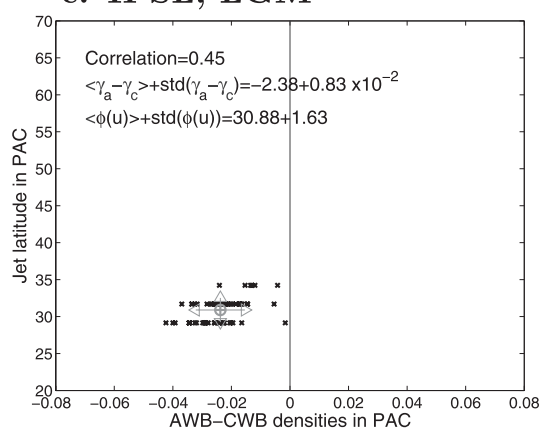

e. CNRM, LGM

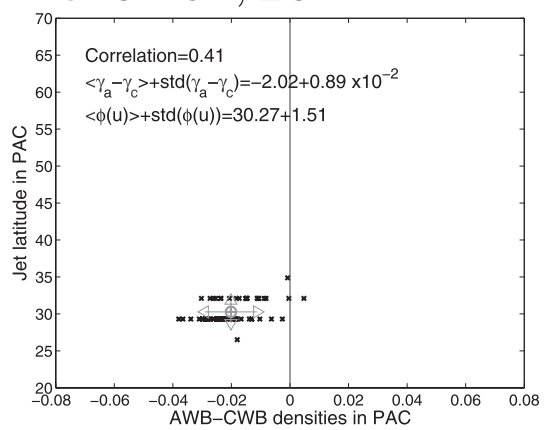

g. MIROC, LGM

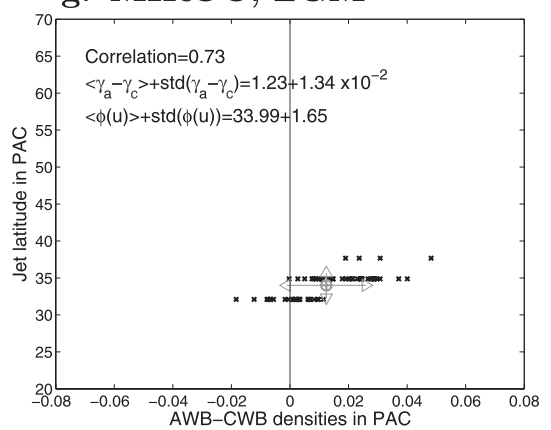

i. HadCM3, LGM

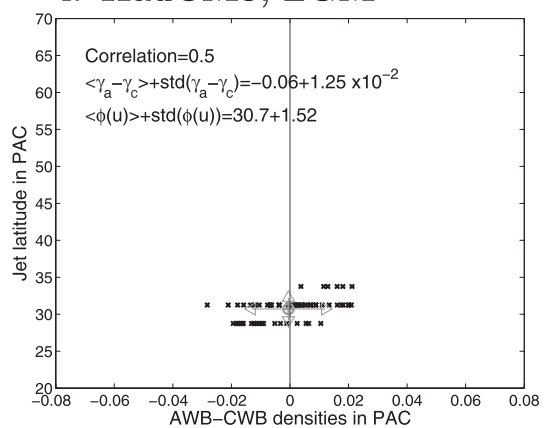

FIG. 4. Latitude of the zonal wind maximum at $500 \mathrm{hPa}[\phi(u)]$ as a function of $\gamma_{a}-\gamma_{c}$ at $200 \mathrm{hPa}$ averaged in the Pacific domain $\left(15^{\circ}-\right.$ $75^{\circ} \mathrm{N}, 150^{\circ} \mathrm{E}-110^{\circ} \mathrm{W}$ ). One black point corresponds to 1 month belonging to the DJF period. (a) ERA-40; simulations of the IPSL CM4 (b) preindustrial and (c) LGM; CNRM-CM3.3 (d) preindustrial and (e) LGM; MIROC3.2 (f) preindustrial and (g) LGM; and HadCM3 (h) preindustrial and (i) LGM. 60 months are represented in (b)-(i) corresponding to the DJF months of each 20-yr simulation while 135 months appear in (a) corresponding to the ERA-40 winter months from 1957 to 2002 . The mean value and the standard deviation of $\gamma_{a}-\gamma_{c}$ and $\phi(u)$ are indicated in each panel as well as the correlation between the two. All of the correlations have been found to be significant at $99 \%$. 


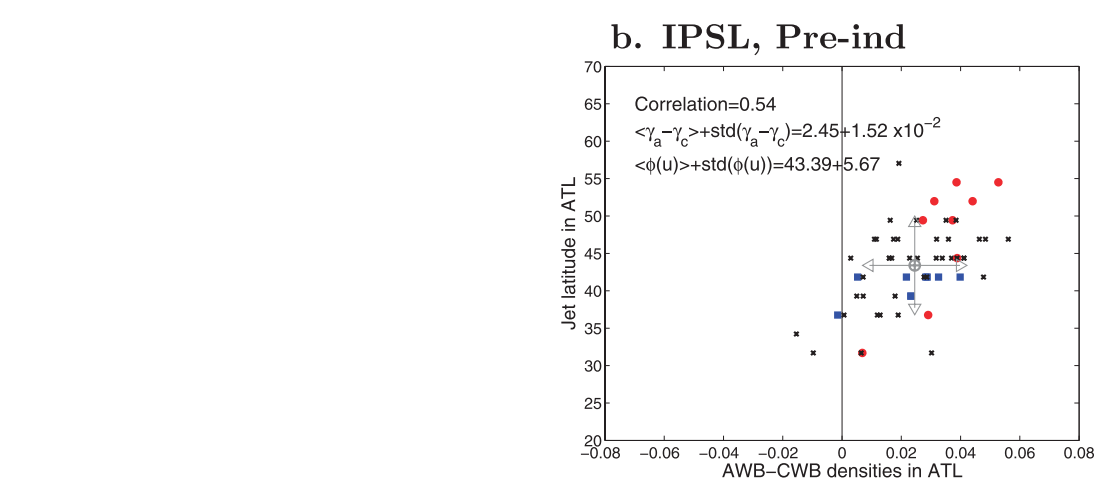

\section{c. IPSL, LGM}

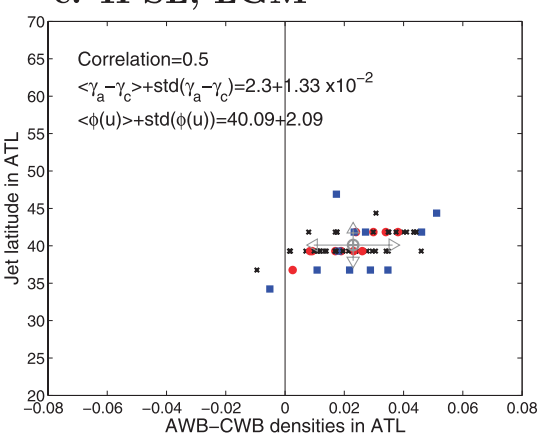

d. CNRM, Pre-ind

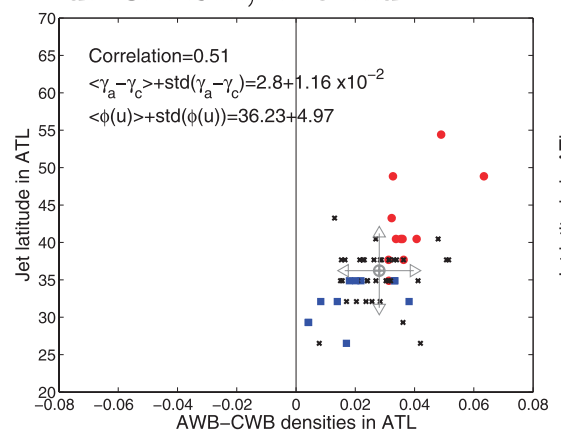

e. CNRM, LGM

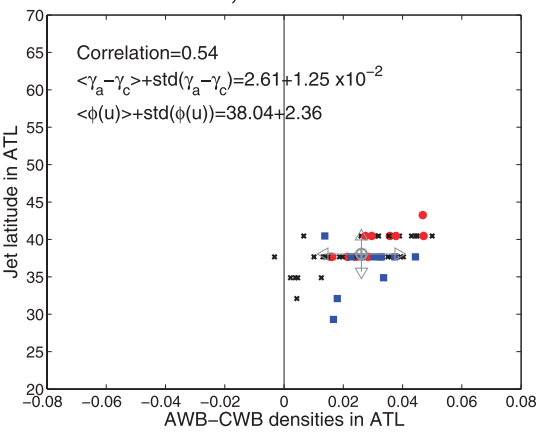

f. MIROC, Pre-ind
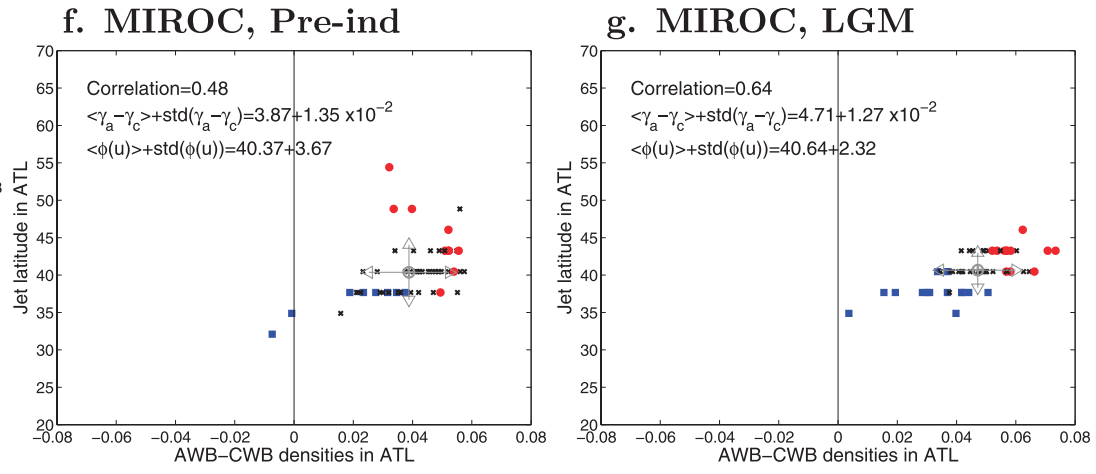

h. HadCM3, Pre-ind

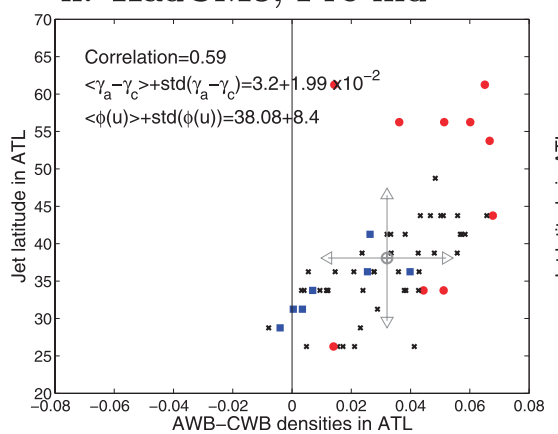

i. HadCM3, LGM

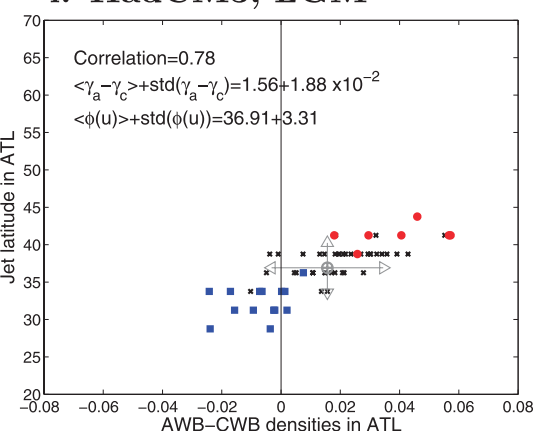

FIG. 5. As in Fig. 4, but for the Atlantic domain $\left(15^{\circ}-75^{\circ} \mathrm{N}, 80^{\circ} \mathrm{W}-10^{\circ} \mathrm{E}\right)$. Red circles and blue squares correspond to values of the first $\mathrm{PC}$ of the Atlantic greater than 1 and less than -1 , respectively. See more details in the text for the definition of the EOF. 
jets are systematically stronger in PREIND, whatever storm track and model is chosen. In the Pacific, the largest difference between LGM and PREIND appears for CNRM-CM3.3 (Figs. 4d,e) and HadCM3 (Figs. 4h,i), while in the Atlantic it occurs for IPSL CM4 (Figs. 5b,c) and HadCM3 (Figs. 5h,i). These features are accompanied by a significant increase of the mean of $\gamma_{a}-\gamma_{c}$ and its standard deviation, as well as an increase of the mean latitude of the jet maximum. Other cases present similar tendencies, but with weaker changes. Among the eight cases shown (four models and two storm tracks), two of them present some exceptions to the general rules previously stated; for example, there is a decrease of the mean of $\gamma_{a}-\gamma_{c}$ from LGM to PREIND for MIROC3.2 in the Atlantic (Figs. 5f,g) and a decrease of the standard deviation of $\gamma_{a}-\gamma_{c}$ for CNRM-CM3.3 in the Atlantic (Figs. 5d,e).

As shown in most panels of Figs. 4-5, the mean latitude of the jet maximum increases slightly from LGM to PREIND. Figure 3 shows a similar result, but from a twodimensional view of the zonal wind circulation. These more southward westerlies can be interpreted as a result of more CWB and less AWB events in the LGM runs.

To summarize, these data present evidence of a significant relationship between high-latitude (low latitude) jets and more AWB (CWB) events. This can be deduced by analyzing the month-to-month variability in each individual simulation as well as by comparing the LGM and PREIND simulations. All of the models in both the Pacific and Atlantic regions exhibit a systematic reduction of the latitudinal fluctuations of the midlatitude jets in LGM compared to PREIND and ERA-40. This weaker variability in LGM is accompanied by a slight southward displacement of the climatological westerlies, especially on the eastern side of the oceanic basins where wave-breaking events are the most frequent. These largescale circulation properties are consistent with the evolution of the frequencies of occurrence of wave-breaking events. There is a tendency toward less AWB and more CWB events in LGM in all cases, except for MIROC3.2 in the Atlantic. Furthermore, the different types of wavebreaking events tend to occur in the same regions in LGM and present less dispersion. However, the close link that exists between the latitude of the eddy-driven jets and the nature of the wave breaking does not, in itself, provide an explanation for their global changes in LGM. A possible mechanism is provided in next section.

\section{4) Physical interpretation}

In R09, the spatial structure of the eddy-driven jets and the nature of the wave breaking were shown to depend strongly on the latitudinal position of the low-level baroclinicity at the entrance of the storm tracks. This conclusion was derived from long-term simulations of an atmospheric primitive equation model forced by a temperature relaxation toward different thermal contrasts located at different latitudes. When the restorationtemperature gradient is located more to the south (e.g., $30^{\circ} \mathrm{N}$ ), baroclinic waves developing downstream from it tend to be northwest-southeast tilted, they usually break cyclonically, and the eddy-driven jet is zonally oriented (it remains more or less at $30^{\circ} \mathrm{N}$ ). In contrast, for a temperature gradient more to the north (e.g., $\left.45^{\circ} \mathrm{N}\right)$, waves get a southwest-northeast orientation and break anticyclonically. The jet gets a southwest-northeast orientation from the beginning to the end of the storm track and may reach $60^{\circ} \mathrm{N}$ at the end.

Because of the ice sheets and $\mathrm{CO}_{2}$ changes at LGM, significant changes appear in the low-level baroclinicity too (e.g., L09; Donohoe and Battisti 2009). The most remarkable feature is the increase of the low-level mean baroclinicity at the entrance of the Atlantic storm track resulting from the presence of the Laurentide Ice Sheet over North America (e.g., cf. the thin dashed and solid lines on the right panels of Fig. 6). Another distinct feature is the weak latitudinal fluctuations of the lowlevel baroclinicity in LGM. In the LGM IPSL CM4 results over the Atlantic, there is less than $5^{\circ}$ in latitude separating the maximum of the mean temperature gradient from that computed when it exceeds its standard deviation (thin and heavy dashed lines in Fig. 6b). In contrast, in the PREIND IPSL CM4 run, the same distance is twice as large, and close to $10^{\circ}$ (thin and heavy solid lines in Fig. 6b). A larger variability in the latitude of the low-level baroclinicity also appears for the CNRM CM4 in the Atlantic (Fig. 6d) and Pacific (Fig. 6c), as well as for HadCM3 and MIROC3.2 (not shown). The fact that the low-level baroclinicity peaks more often at higher latitudes in PREIND than in LGM favors the emergence of more AWB events, consistent with the results of R09. In other words, the underlined mechanism is the following: in LGM, a weak variability of the low-level baroclinicity tends to create the same type of breaking events downstream, maintaining the eddydriven jet almost at the same position, while in PREIND, a stronger variability favors the emergence of different kinds of breaking, displacing the eddy-driven jet over a larger band of latitudes. This will be confirmed by the analysis of a sensitivity experiment considering all of the LGM forcings except the ice sheet topography in section $4 \mathrm{~b}(3)$.

\section{b. Northern Hemisphere modes of variability: $A O$ and $N A O$}

Because the fluctuations of the Northern Hemisphere eddy-driven jets are closely related to two major modes of 
a. PACIFIC, IPSL

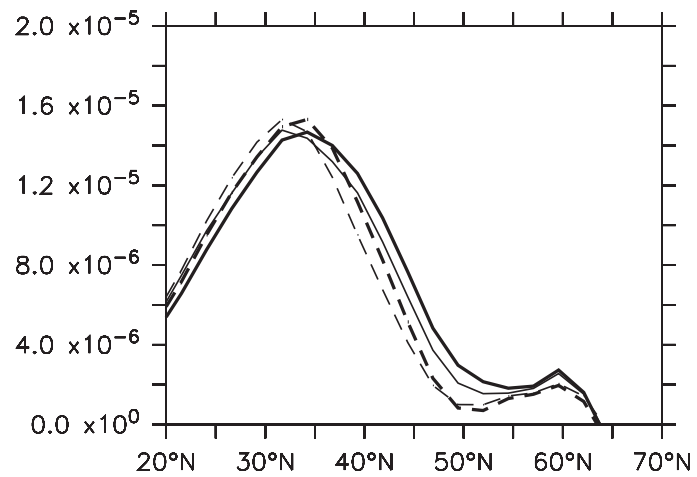

C. PACIFIC, CNRM

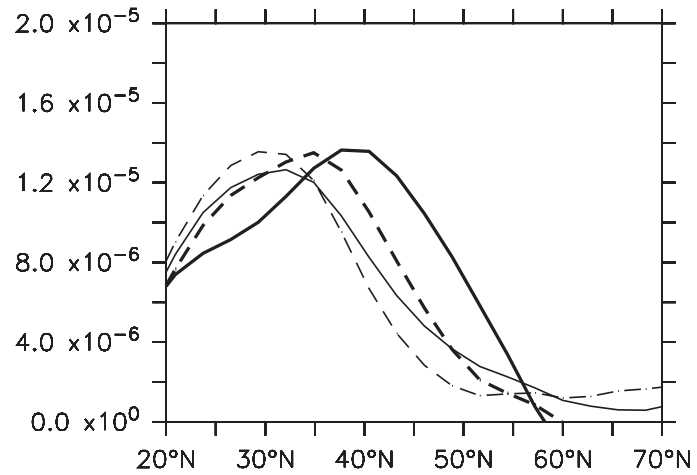

b. ATLANTIC, IPSL

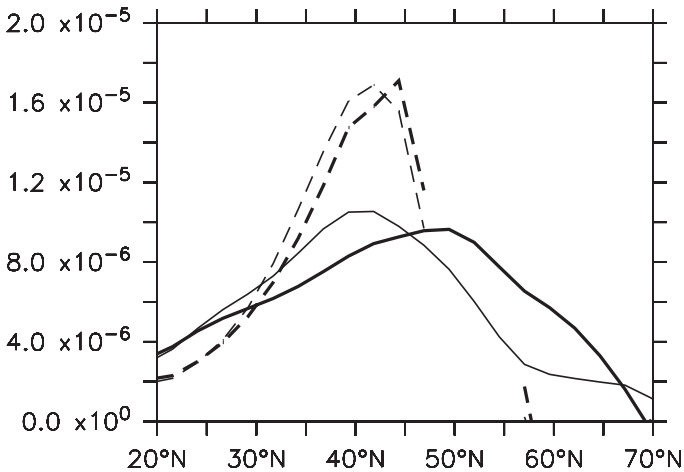

d. ATLANTIC, CNRM

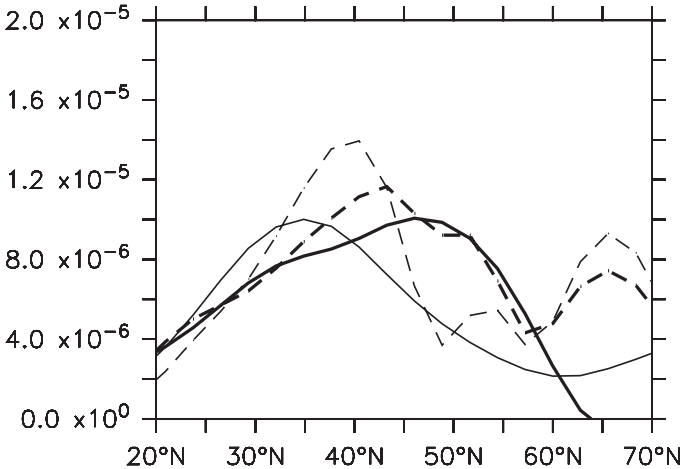

FIG. 6. Time mean of the temperature gradient at $700 \mathrm{hPa}$ longitudinally averaged at the entrance of each storm track $\left(120^{\circ}-150^{\circ} \mathrm{E}\right.$ for the Pacific and $80^{\circ}-60^{\circ} \mathrm{W}$ for the Atlantic) as a function of latitude (thin dashed lines for LGM and thin solid lines for the preindustrial simulation). Composite of the temperature gradient at $700 \mathrm{hPa}$ when the latitude of its maximum exceeds its standard deviation (heavy dashed lines for LGM and heavy solid lines for the preindustrial simulation).

atmospheric variability of the Northern Hemispherethe $\mathrm{AO}$ and $\mathrm{NAO}$ - the properties of the latter modes are hereafter investigated to make the link with the previous section. The AO is first described to get a global hemispheric perspective before analyzing the NAO, which exhibits more local effects.

\section{1) The Arctic Oscillation}

Here, the AO is defined as the leading empirical orthogonal function (EOF) of the geopotential height field at $850 \mathrm{hPa}$ poleward of $20^{\circ} \mathrm{N}$, which is quite similar to that based on sea level pressure anomalies (Thompson and Wallace 2000). The AO pattern in ERA-40 data (Fig. 7a) is characterized by zonally symmetric geopotential anomalies of opposite signs in the polar region and in the surrounding zonal ring centered near $45^{\circ} \mathrm{N}$. The equivalent EOF patterns in all of the preindustrial simulations of the four models (second column of Fig. 7) present similar dipolar anomalies. The local centers of variability are also quite close to each other. In the polar region, two local minima appear south of Greenland and over the Arctic at $100^{\circ} \mathrm{E}$, and in middle latitudes two major centers of positive geopotential anomalies are clearly located over the middle Pacific and eastern Atlantic. However, some slight discrepancies exist in the model PREIND outputs, especially in terms of the amplitude reached by the anomalies.

The LGM EOFs (third column of Fig. 7) also present dipolar geopotential anomalies but they are less zonally symmetric than in the PREIND cases. Furthermore, a global southward displacement of the anomalies can be noticed by looking at the position of the node of the leading EOF. It appears everywhere except in the eastern Pacific for MIROC3.2. More precisely, in the Atlantic sector, the trough over Greenland in PREIND is displaced toward the southeast between Iceland and Ireland in LGM for every model. This is accompanied by a southward displacement of the gradients of the geopotential anomalies that are usually located around the node of the leading geopotential EOF.

Even though the four models tend to exhibit similar changes in the AO pattern from PREIND to LGM simulations, they are not the same as those revealed by previous studies (e.g., Otto-Bliesner et al. 2006; Justino 


\section{b. IPSL, Pre-ind}

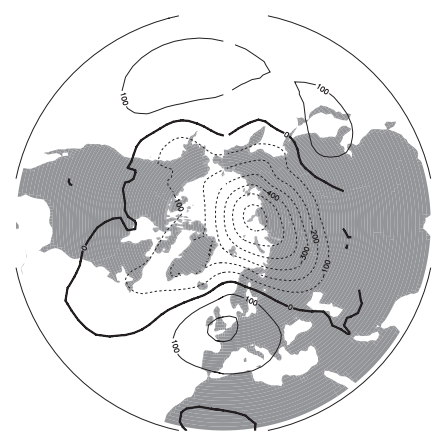

d. CNRM, Pre-ind

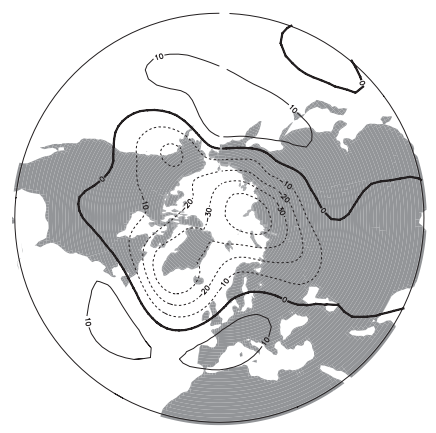

f. MIROC, Pre-ind

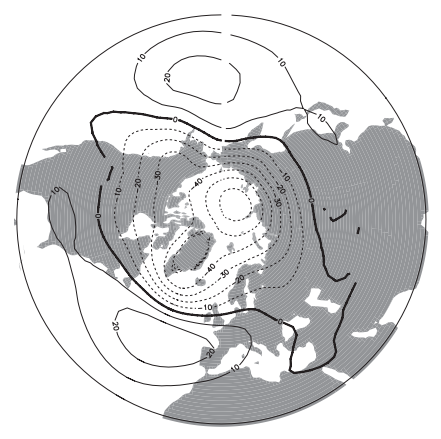

h. HadCM3, Pre-ind

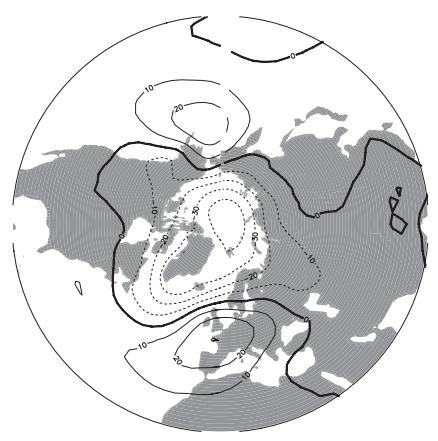

c. IPSL, LGM

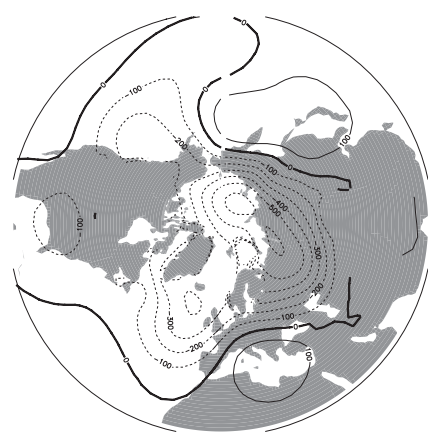

e. CNRM, LGM

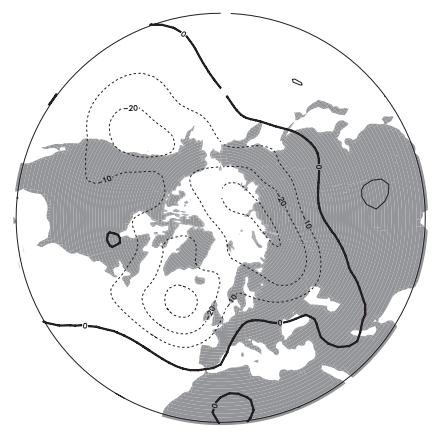

g. MIROC, LGM

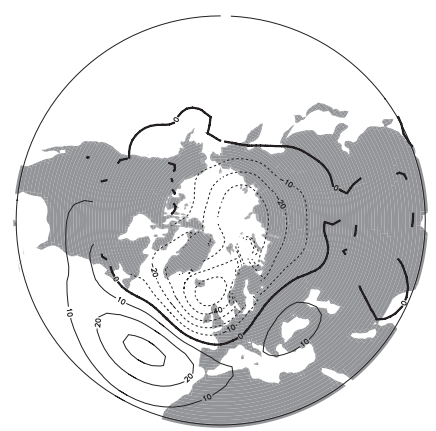

i. HadCM3, LGM

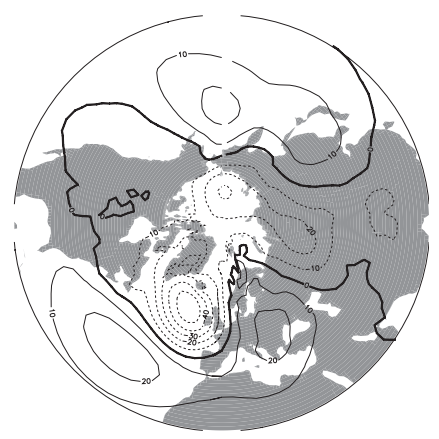

FIG. 7. Leading EOF of the geopotential height at $850 \mathrm{hPa}$ in the Northern Hemisphere corresponding to the AO in (a) ERA-40, and (left) preindustrial and (right) LGM simulations (contour interval of $10 \mathrm{~m}$ ). (b), (c) IPSL CM4, (d),(e) CNRM-CM3.3, (f),(g) MIROC3.2, and (h),(i) HadCM3. 
and Peltier 2008). Otto-Bliesner et al. (2006) found weaker AO centers of variability in LGM using the NCAR Community Climate System Model, version 3 (CCSM3) coupled model, while the study of Justino and Peltier (2008) revealed an intensification of the $\mathrm{AO}$ variability under LGM conditions using the NCAR Climate System Model, version 1 (CSM1.4), but with different resolutions, parameters, and forcings. In the present study, all four models reproduce a southward shift of the geopotential anomalies from PREIND to LGM. However, it seems difficult to conclude on a global evolution of the intensity of the AO variability because most of them present a local displacement of the anomalies but not a global change of their amplitude.

The regression of the monthly zonal wind at $500 \mathrm{hPa}$ upon the monthly leading principal component (PC) time series is shown on Fig. 8a for ERA-40 data. The node of the regression is close to the maximum of the time mean zonal wind at almost all of the longitudes of the Atlantic sector, showing that the Atlantic eddy-driven jet is displaced poleward for high PC values. The same appears in the eastern Pacific, but with weaker amplitudes. For the PREIND simulations (second column of Fig. 8) and the Atlantic sector, the node of the regression is still around the jet maximum for all models (except for IPSL CM4 in the western Atlantic, but with small values) even though the amplitude of the regression differs from one model to another. In the eastern Pacific, dipolar wind anomalies with opposite signs appear on each side of the jet maximum for IPSL CM4 (Fig. 8b), CNRM-CM3.3 (Fig. 8d), and MIROC3.2 (Fig. 8f), but not for HadCM3 (Fig. 8h). In ERA-40 and PREIND simulations, the AO variability is characterized by meridional shifting of the eddy-driven jets with larger variations in the Atlantic sector.

We now compare the LGM and PREIND zonal wind regressions. Positive zonal wind anomalies are collocated with time-mean zonal wind maxima in the eastern Pacific and in the Atlantic for the LGM IPSL CM4 (Fig. 8c) and CNRM CM3.3 (Fig. 8e) models. For these two models, the LGM AO variability is characterized by simultaneous pulsing of the Pacific and Atlantic eddy-driven jets. For MIROC3.2 (Fig. 8g), in the Pacific, the anomalies are weak and correspond more to a meridional shifting of the jet. In the Atlantic, the node of the regression is slightly located to the south of the jet maximum corresponding to both an acceleration and a poleward displacement of the jet for high PC values as for LGM HadCM3 (Fig. 8i). Thus, the LGM AO variability is more characterized by acceleration-deceleration of the jets rather than meridional shifting, which is consistent with the southward displacement of the EOF geopotential gradients shown in Fig. 7.

\section{2) The North Atlantic Oscillation}

To make the link with recent studies on the NAO and wave-breaking events (e.g., Benedict et al. 2004; Rivière and Orlanski 2007), the principal mode of low-frequency variability in the Atlantic is studied in the present section. The first EOF of the geopotential height at $850 \mathrm{hPa}$ is computed over a domain covering the Atlantic $\left(20^{\circ}-70^{\circ} \mathrm{N}\right.$, $90^{\circ} \mathrm{W}-40^{\circ} \mathrm{E}$ ) for each dataset. For the ERA- 40 data, the first EOF corresponds to the typical dipole pattern of the NAO. By extension of the results from the ERA-40 data, the first EOF in each simulation will be called NAO even though it does not necessarily have a dipole structure. Furthermore, the choice of the positive phase is made such that the principal component is positively correlated with the jet latitude. Composites computed for values of the first PC greater than 1 and less than -1 will be considered as composites of the positive and negative phase of the NAO, respectively. A month with PC greater than 1 (less than -1 ) is called a positive (negative) month.

In ERA-40, it is well known that the positive phase of the NAO is characterized by a double-jet structure with an eddy-driven jet located more to the north than usual and well separated from the subtropical African jet (e.g., Vallis and Gerber 2008). This remarkable feature is clearly visible (Fig. 9b) as is the southwest-northeast orientation of the eddy-driven jet. In contrast, the negative phase exhibits a more zonally oriented eddy-driven jet that extends to the subtropical African jet (Fig. 9c). The occurrence of AWB events is much more frequent during the positive phase than during the negative phase, and CWB events are slightly less frequent (Figs. 5a and $9 b, c)$. This is consistent with the recent studies of the NAO that were mentioned in the introduction. In Fig. 5a, positive months (red circles) and negative months (blue squares) form an accumulation of points in two well-separated areas of the clouds of points. In Fig. 5a, the separation of the points means that the positive (negative) phase of the NAO is characterized by high (low) values of $\gamma_{a}-\gamma_{c}$ accompanied by high-latitude (low latitude) eddy-driven jets. As shown on Fig. 9a, the positive and negative phases of the NAO differ in the latitude of the Atlantic eddy-driven jet; for the positive phase the zonal-mean zonal wind reaches its maximum at $50^{\circ} \mathrm{N}$, while for the negative phase this is reached at $35^{\circ} \mathrm{N}$. The ERA-40 NAO is therefore characterized by meridional shifting of the Atlantic eddy-driven jet and not by its pulsing.

The first mode of variability in the PREIND simulations of the four models bears some resemblance with the ERA-40 NAO as shown by the composites for the two phases of each leading EOF. The positive phase presents a double-jet structure at the end of the Atlantic 
b. IPSL, Pre-ind

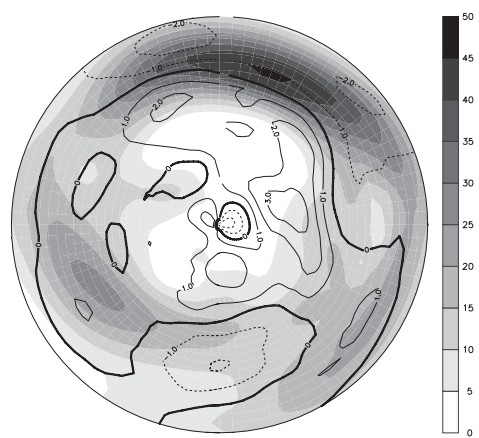

d. CNRM, Pre-ind

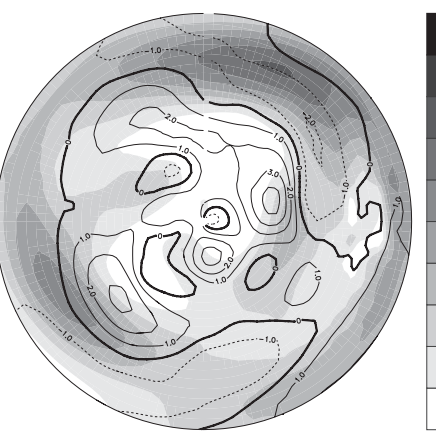

f. MIROC, Pre-ind

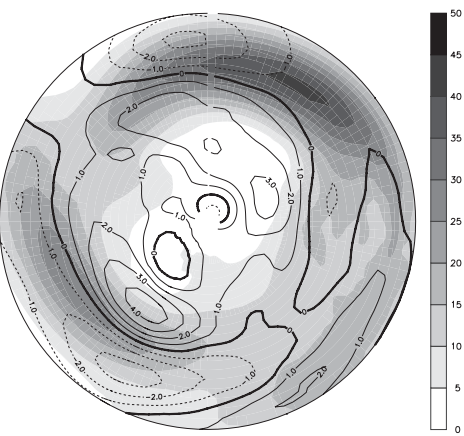

h. HadCM3, Pre-ind

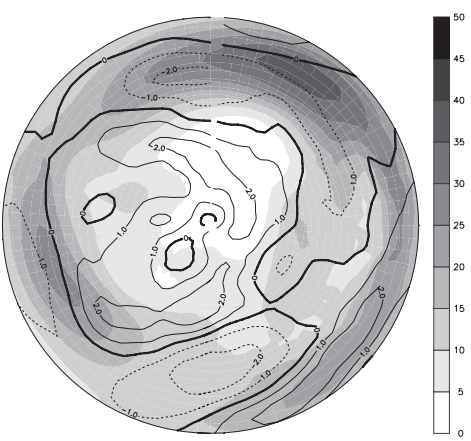

c. IPSL, LGM

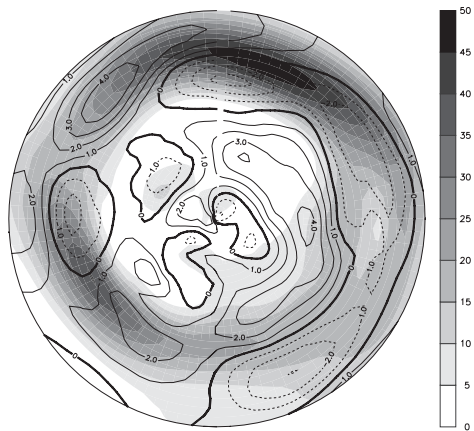

e. CNRM, LGM

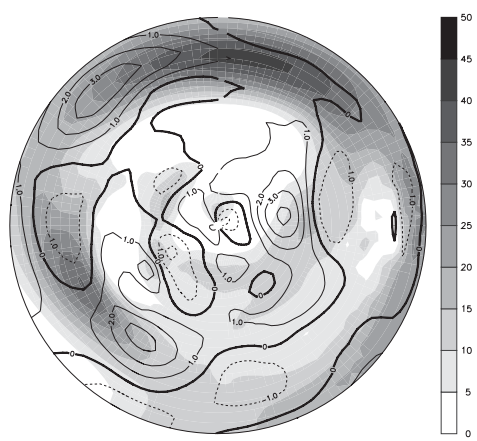

g. MIROC, LGM

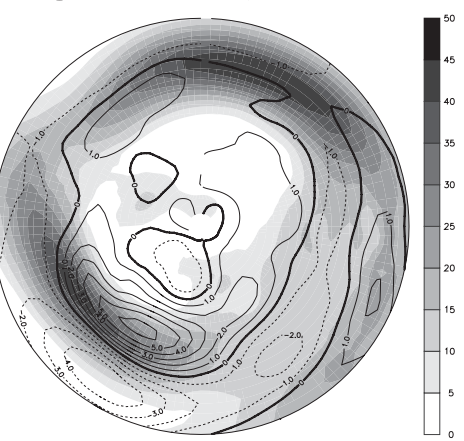

i. HadCM3, LGM

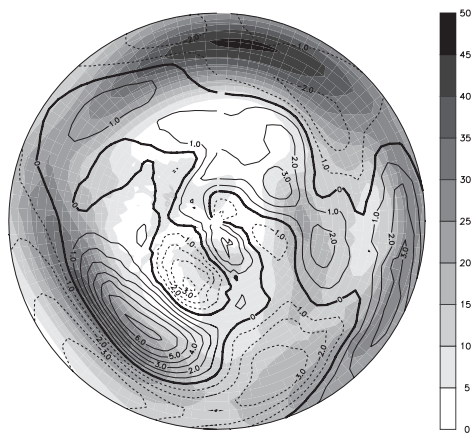

FIG. 8. Regression of the zonal wind at $500 \mathrm{hPa}$ onto the standardized leading PC time series of the Northern Hemisphere (black dashed and solid contours for negative and positive values, respectively; interval of $1 \mathrm{~m} \mathrm{~s}^{-1}$ ) and the timemean zonal wind at $500 \mathrm{hPa}$ (shadings; interval of $5 \mathrm{~m} \mathrm{~s}^{-1}$ ) in (a) ERA-40, and (left) preindustrial and (right) LGM simulations. (b),(c) IPSL CM4, (d),(e) CNRM-CM3.3, (f),(g) MIROC3.2, and (h),(i) HadCM3 are shown. Same stereographic projection as in Fig. 7. 


\section{a. u composites, $500 \mathrm{hPa}$}

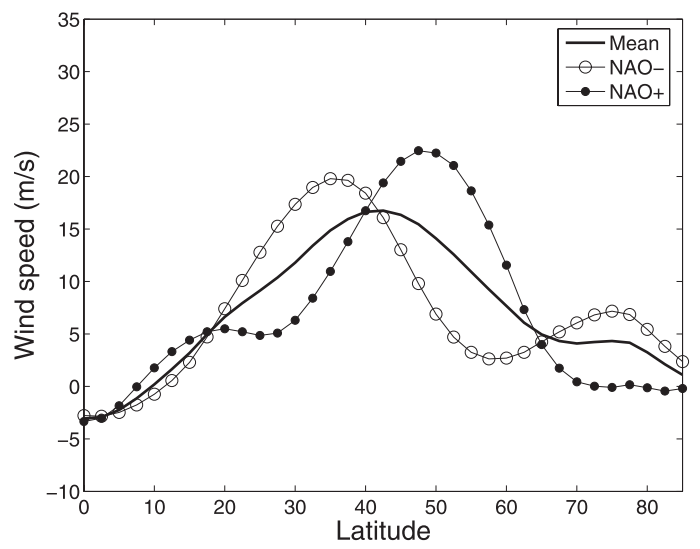

b. NAO Positive phase

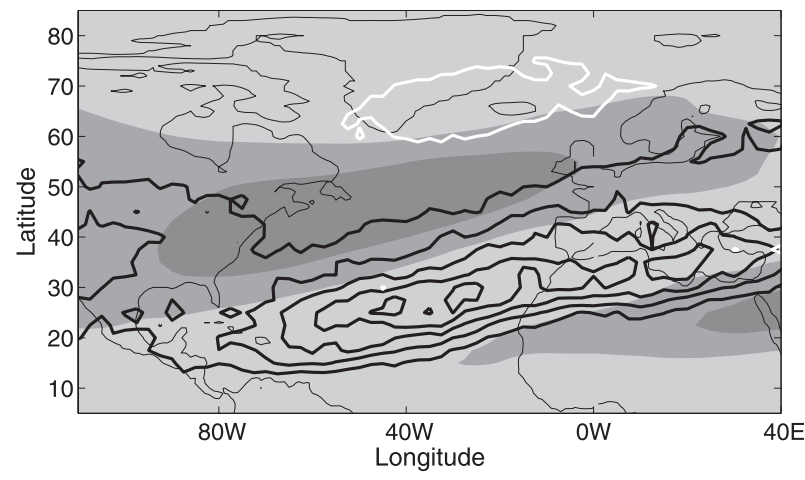

c. NAO Negative phase

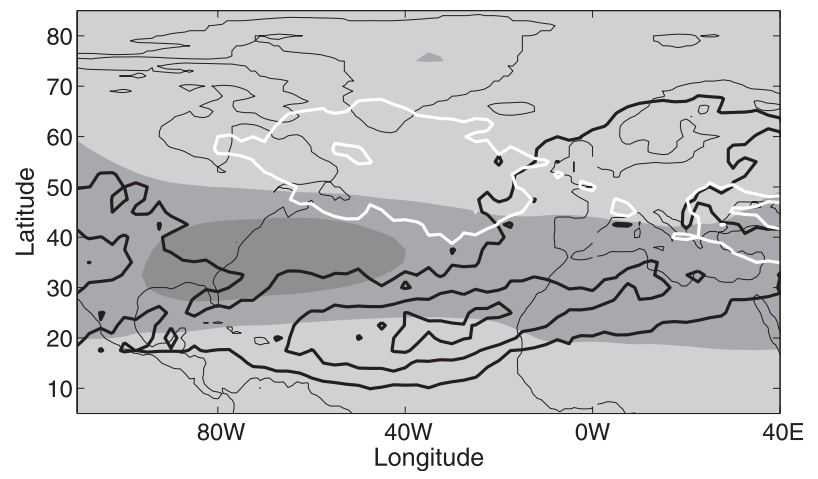

FIG. 9. Wave-breaking events and jet properties during the different phases of the NAO in ERA-40. (a) Composites of the zonalmean zonal wind at $500 \mathrm{hPa}$ in the Atlantic sector $\left(80^{\circ} \mathrm{W}-10^{\circ} \mathrm{E}\right)$ for all winter months (thick solid line), positive NAO months (line with filled black circles), and negative NAO months (line with open black circles). (b),(c) $\gamma_{c}$ (white contours; interval of $0.05 \mathrm{day}^{-1}$ ) and $\gamma_{a}$ (black contours; interval of $0.05 \mathrm{day}^{-1}$ ) at $200 \mathrm{hPa}$ and the zonal wind at $500 \mathrm{hPa}$ (interval of $10 \mathrm{~m} \mathrm{~s}^{-1}$ ) for the positive and negative phase, respectively. The percentage of the variance explained by the first EOF is $37.6 \%$. storm track and the main Atlantic jet is southwestnortheast oriented (Figs. 10c, 11c, 12c, and 13c), while a more zonally oriented Atlantic jet located more to the south appears during the negative phase (Figs. 10e, 11e, $12 \mathrm{e}$, and 13e). Figures 10a, 11a, 12a, and 13a reveal that the PREIND NAO of the four models is characterized by meridional shifting of the jet; the distance between the two zonal wind maxima of the two extreme phases is $\sim 12^{\circ}$ latitude for IPSL CM4, $10^{\circ}$ for CNRM-CM3.3, $10^{\circ}$ for MIROC3.2, $25^{\circ}$ for HadCM3, and $15^{\circ}$ for ERA40. Except for HadCM3, the models tend to reproduce slightly weaker latitudinal fluctuations of the jet than in ERA-40. In addition, in contrast with ERA-40 (Fig. 9a), all the models tend to create a stronger jet during the negative phase than during the positive phase (Figs. 10a, 11a, 12a, and 13a).

In terms of wave-breaking composites, the PREIND simulations present the same tendencies as those in ERA-40, but with less contrasts between the two phases of the NAO, especially for IPSL CM4. In the latter model, AWB and CWB densities reach more or less the same maximum values during the different phases of the NAO, but AWB events span a larger area during the positive phase and CWB events are larger during the negative phase (cf. Figs. 10c,e). In CNRM-CM3.3, there is an increase of $\gamma_{a}$ maxima as well as a spatial extension of the area covered by large values of $\gamma_{a}$ during the positive phase (Figs. 11c,e), while for $\gamma_{c}$ the changes are less clear. For MIROC3.2 and HadCM3, both an increase of $\gamma_{a}$ and a decrease of $\gamma_{c}$ clearly appears from negative to positive months (see Figs. 12c,e and Figs. 13c,e).

The separation between the positive and negative months in terms of wave breaking and jet latitude is also visible in the month-to-month variations shown on Fig. 5. Negative months and positive months of PREIND simulations (Figs. 5b,d,f,h) tend to be located more on the lower-left and upper-right sides, respectively, of each scatterplot, even though their separation is less well marked than in ERA-40 (Fig. 5a). The fact there are even two positive months in IPSL CM4 for which the reverse occurs (i.e., the jet latitude is lower than that for negative months) is due to our methodology. For these two particular months, there is a poleward shift of the jet in a limited longitudinal band from $40^{\circ} \mathrm{W}$ to $0^{\circ}$, which is not detected by the maximum of the longitudinal average in the $80^{\circ} \mathrm{W}-10^{\circ} \mathrm{E}$ sector. In other words, our approach based on a large longitudinal average does not provide some details on the two-dimensional aspect of particular months. The same remark is valid for the unexpected position of the three positive months far to the south for HadCM3 (Fig. 5h). To conclude, the PREIND NAOs correctly capture the latitudinal vacillation of the observed 
a. Pre-ind, u composites, $500 \mathrm{hPa}$

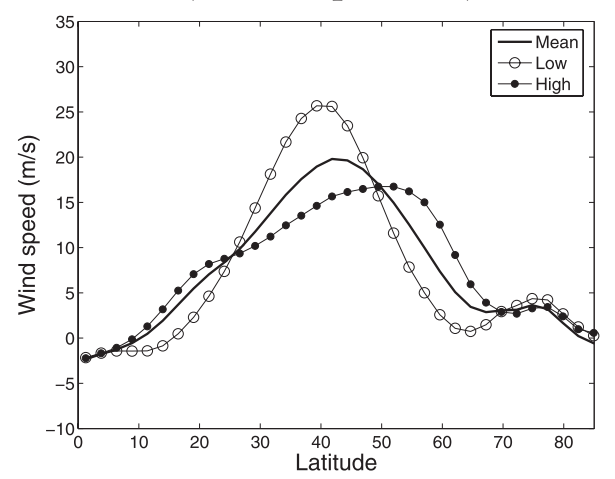

c. Pre-ind, High index

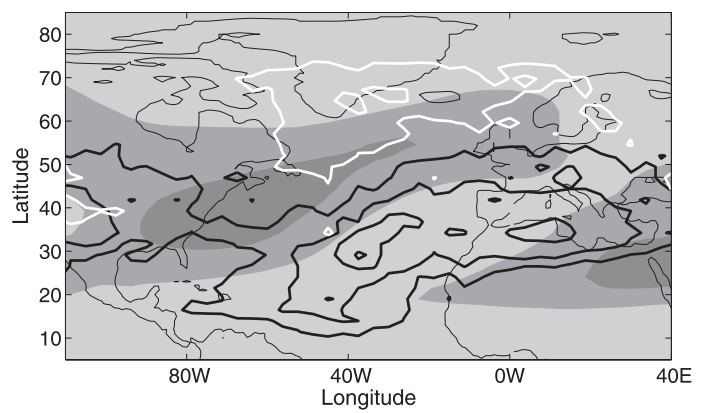

e. Pre-ind, Low index

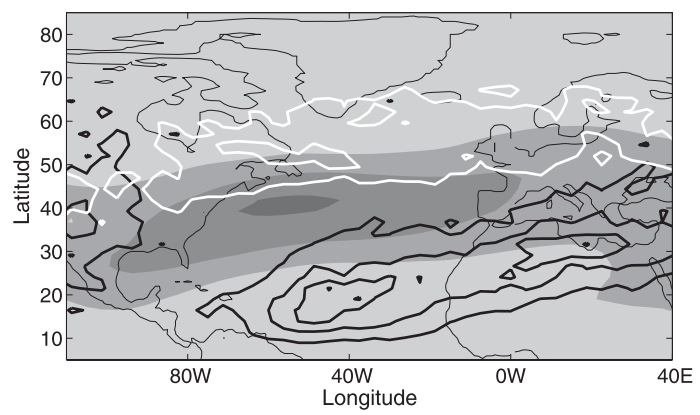

b. LGM, u composites, $500 \mathrm{hPa}$

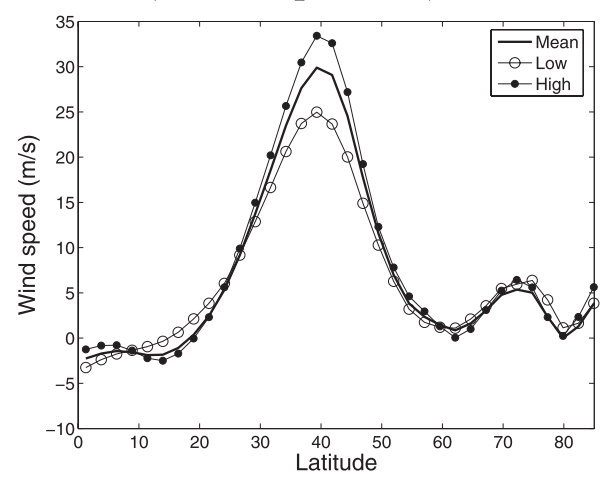

d. LGM, High index

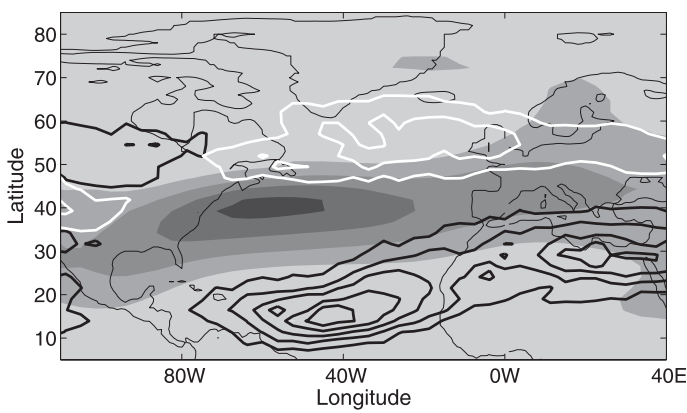

f. LGM, Low index

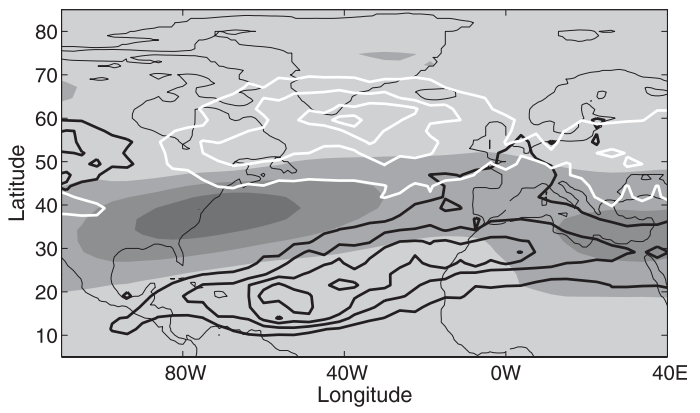

FIG. 10. As in Fig. 9, but for the (left) PREIND and (right) LGM simulations of IPSL CM4. Percentage of the variance explained by the first EOF is $29.8 \%$ for PREIND and $39.0 \%$ for LGM.

Atlantic jet as well as the difference of wave-breaking events during the different phases of the NAO, despite some discrepancies.

The LGM NAO is drastically different from the PREIND one. A systematic comparison of Figs. 10a,b, 11a,b, 12a,b, and 13a,b shows that the latitudinal fluctuations of the Atlantic eddy-driven jet for the leading mode of variability are significantly reduced. In particular, for models such as CNRM-CM3.3 and IPSL CM4 there is not even a significant latitudinal shift from one phase to another (see Figs. 10b and 11b), and the positive phase is no longer characterized by a double-jet structure. In those cases, the LGM NAO is characterized by decelerations and accelerations of the eddy-driven jet. Similarly to these changes in the jet, the wave-breaking densities extend more to the east during the positive phase of the NAO (Figs. 10d,f and 11d,f). However, no systematic change in the nature itself of the wavebreaking events is detected from one phase to another. In terms of month-to-month variability, positive and negative months are mixed in the scatterplots of Figs. 5c,e corresponding, respectively, to CNRM-CM3.3 and IPSL CM4, while for the other two models (MIROC3.2 and HadCM3) this separation still exists (Figs. 5g,i).

To summarize, ERA-40 and PREIND NAOs are characterized by large latitudinal fluctuations of the eddy-driven 
a. Pre-ind, u composites, $500 \mathrm{hPa}$

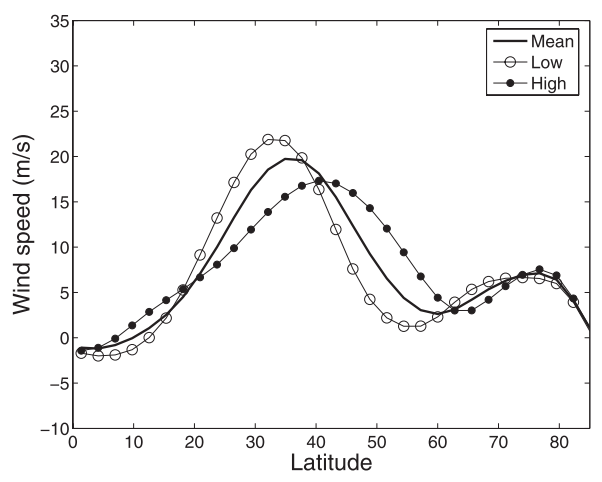

c. Pre-ind, high index

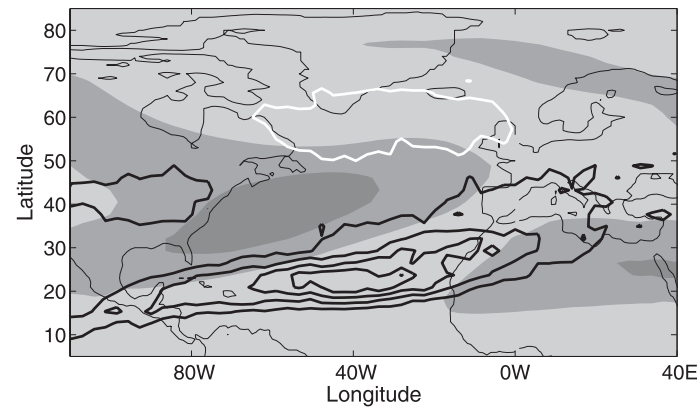

e. Pre-ind, low index

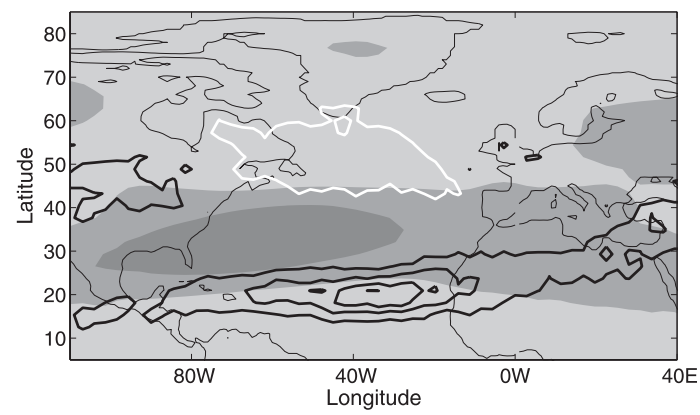

b. LGM, u composites, $500 \mathrm{hPa}$

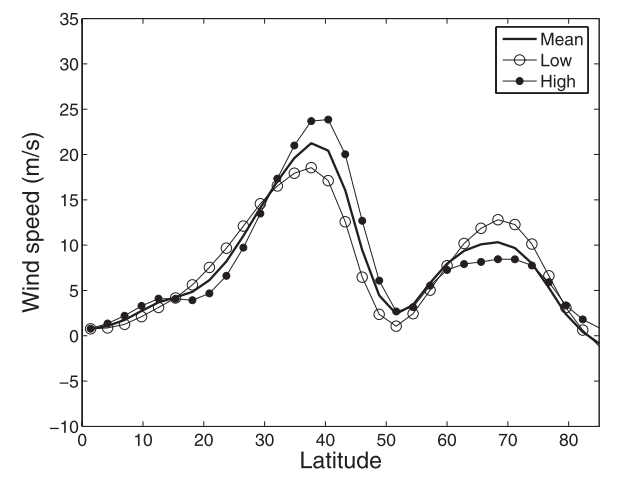

d. LGM, high index

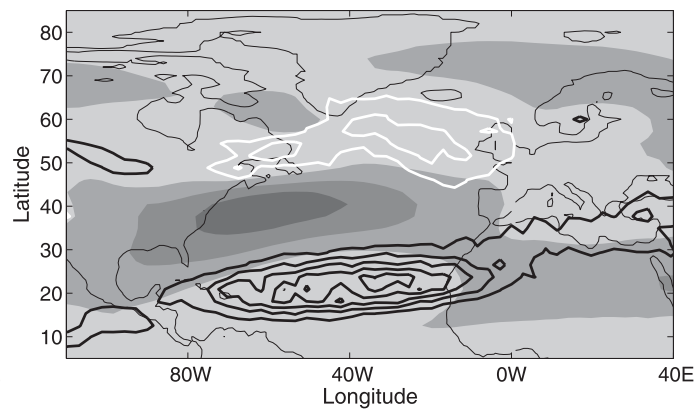

f. LGM, low index

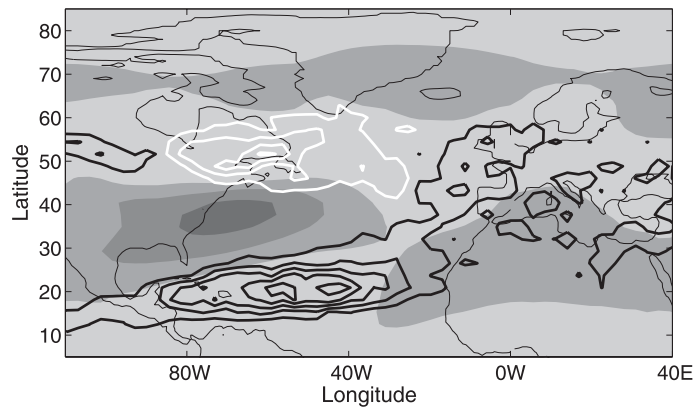

FIG. 11. As in Fig. 9, but for the (left) PREIND and (right) LGM simulations of CNRM-CM3.3. Percentage of the variance explained by the first EOF is $31.8 \%$ for PREIND and $36.8 \%$ for LGM.

jets accompanied by changes in the nature of the wavebreaking events. In contrast, LGM NAOs present less latitudinal fluctuations and even in some models such as IPSL CM4 and CNRM-CM3.3, these fluctuations have almost disappeared entirely. In the two latter cases, LGM NAOs tend to be more characterized by decelerationacceleration or retraction-extension of the eddy-driven jet.

The $e$-folding time scales of the AO and NAO are shown in Table 2 . The daily AO or NAO index is first computed by projecting the daily geopotential height at $850 \mathrm{hPa}$ onto the monthly EOF. The $e$-folding time scale is then defined as the day lag at which the autocorrelation function computed from the daily index falls below $1 / e$. The $e$-folding time scales of the ERA-40 NAO and AO are, respectively, 10 and 14 days, which are close to the values found by previous studies (e.g., Feldstein 2000; Keeley et al. 2009). The PREIND NAO time scales vary between 4 days and 11 days while the PREIND AO varies between 9 and 15 days. The slightly longer time scale of the AO compared to the NAO is usually reproduced by the models. It is impossible, however, to conclude a general tendency from PREIND to LGM; some models tend to slightly shorten the time scale of the NAO (CNRM-CM3.3, IPSL CM4, and MIROC3.2), while others (HadCM3) do the reverse. 
a. Pre-ind, u composites, $500 \mathrm{hPa}$

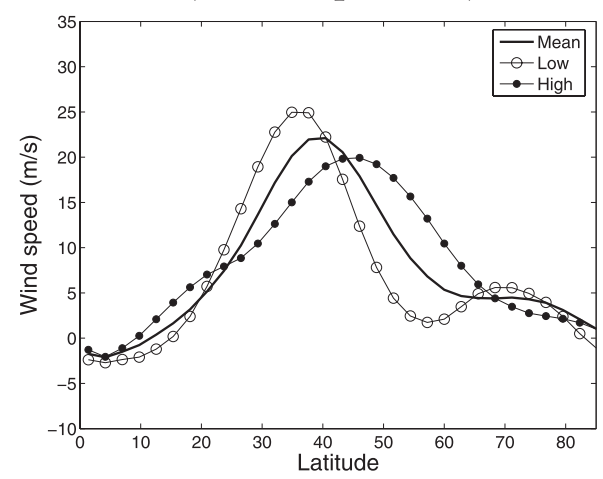

c. Pre-ind, high index

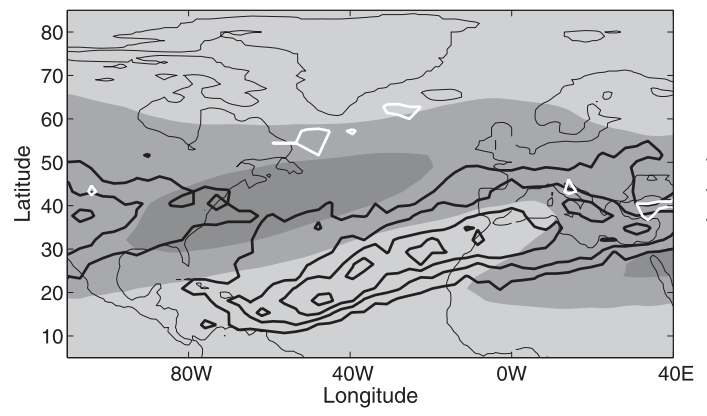

e. Pre-ind, low index

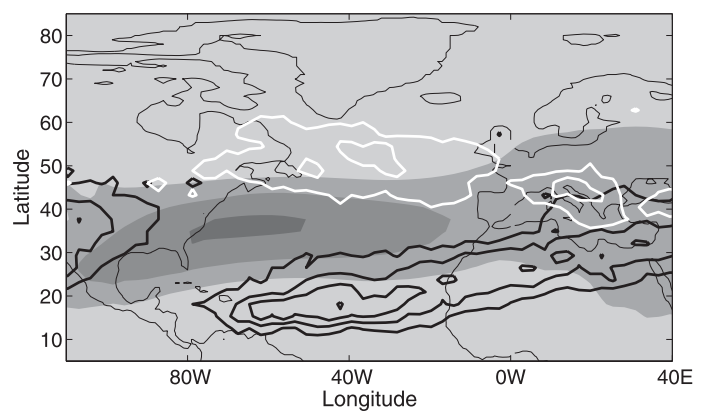

b. LGM, u composites, $500 \mathrm{hPa}$

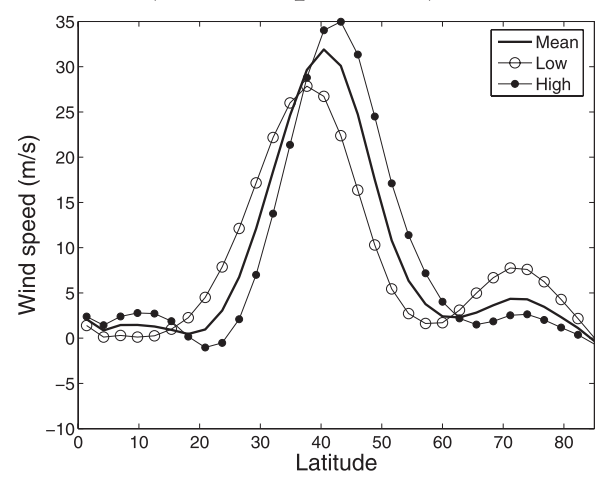

d. LGM, high index

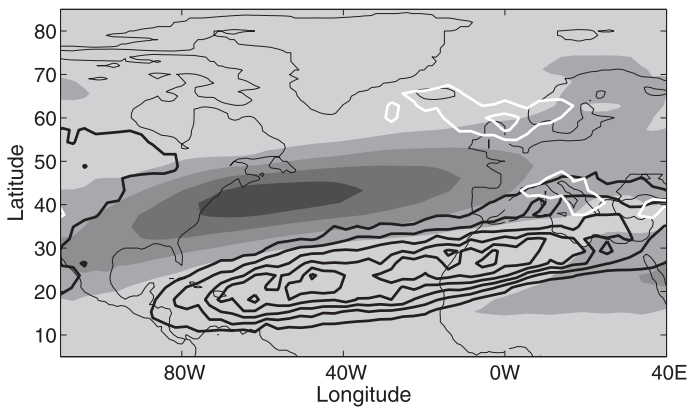

f. LGM, low index

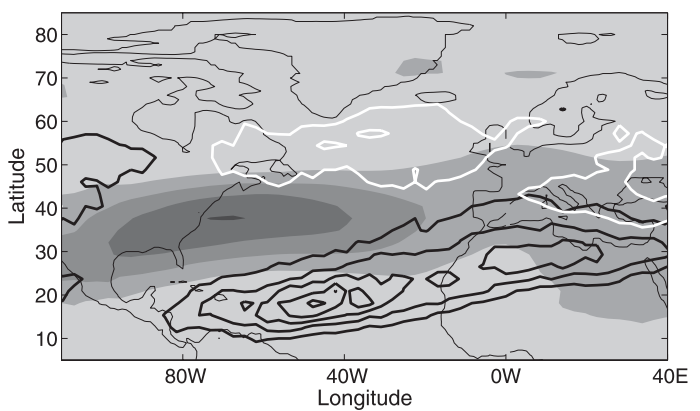

FIG. 12. As in Fig. 9, but for the (left) PREIND and (right) LGM simulations of MIROC3.2. Percentage of the variance explained by the first EOF is $36.4 \%$ for PREIND and $40.0 \%$ for LGM.

\section{3) THE TOPOGRAPHY EFFECT}

The topography of the ice sheets has been recognized as playing a key role in the wintertime-mean atmospheric circulation of the Last Glacial Maximum (e.g., Kageyama and Valdes 2000; Justino et al. 2005, 2006), and seems to be more important than the effect of albedo, greenhouse gas concentrations, and orbital parameters. In the present study, a sensitivity simulation (hereafter denoted as LGM-TOPO-PREIND) has been performed with CNRM-CM3.3 to investigate the impact of the topography on the latitudinal fluctuations of the jet and the NAO. This simulation has all the forcings of the
LGM simulation, except for the topography, which is that of PREIND. The LGM-TOPO-PREIND NAO (Fig. 14) appears to be very similar to the PREIND NAO (Figs. 11a,c,e) and very different from the LGM NAO (Figs. $11 \mathrm{~b}, \mathrm{~d}, \mathrm{f})$. The zonal wind composites of the two extreme phases of the LGM-TOPO-PREIND and PREIND NAOs are very close to each other. Furthermore, the positive phase of the LGM-TOPO-PREIND NAO differs from the negative phase by the nature of the wave breaking similarly to the PREIND NAO. The only difference between the two simulations consists of slightly more eastward-extended jets in LGM-TOPO-PREIND, especially during the positive phase. To conclude, the ice 
a. Pre-ind, u composites, $500 \mathrm{hPa}$

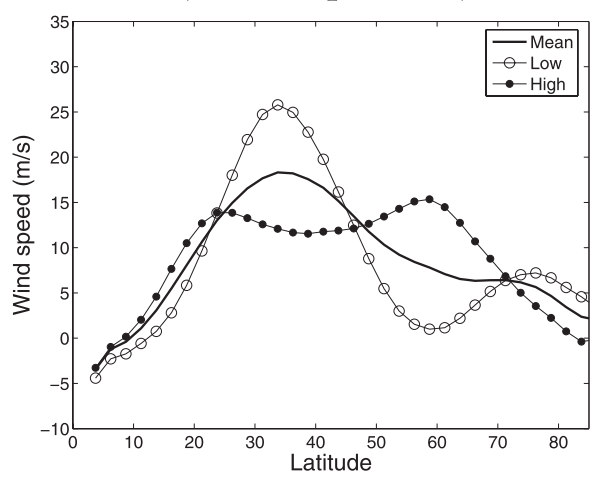

c. Pre-ind, high index

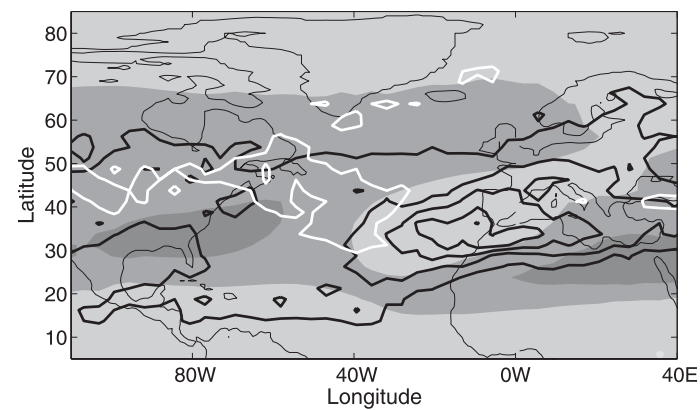

e. Pre-ind, low index

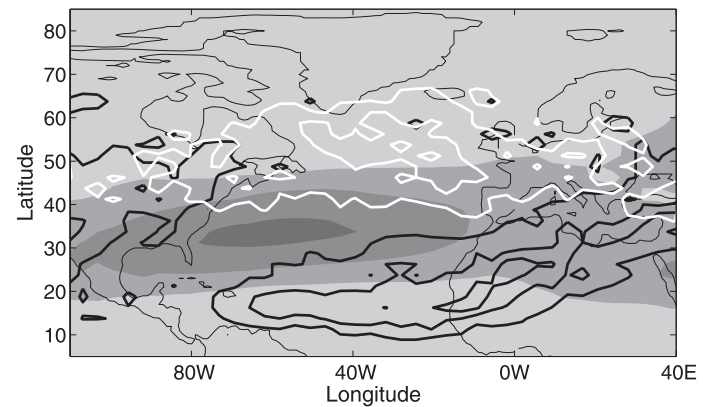

b. LGM, u composites, $500 \mathrm{hPa}$

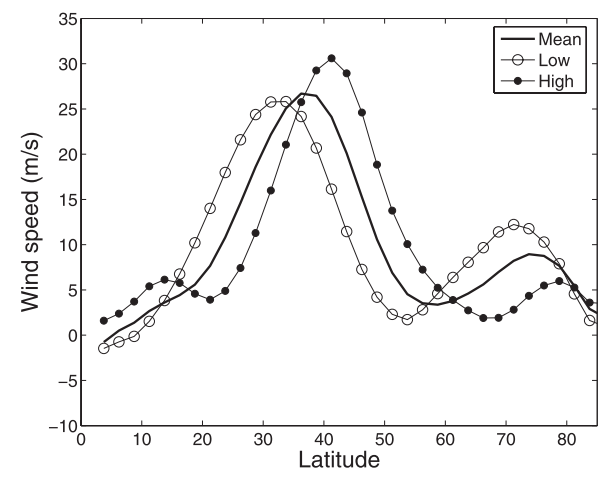

d. LGM, high index

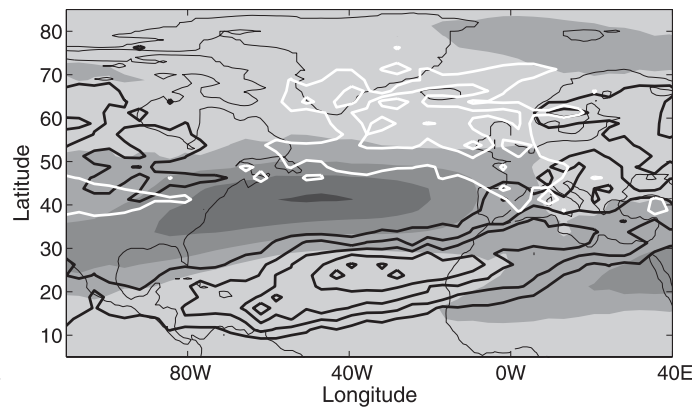

f. LGM, low index

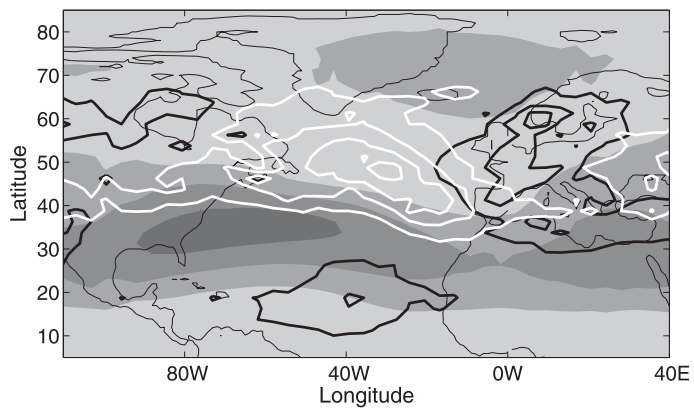

FIG. 13. As in Fig. 9, but for the (left) PREIND and (right) LGM simulations of HadCM3. Percentage of the variance explained by the first EOF is $32.5 \%$ for PREIND and $51.9 \%$ for LGM.

sheet topography is the key factor that determines the main characteristics of the low-frequency atmospheric variability during the Last Glacial Maximum.

To check the robustness of the physical interpretation provided in section $4 \mathrm{a}(4)$, the interannual fluctuations of the low-level baroclinicity at the entrance of the Atlantic storm track have been computed for the LGM-TOPOPREIND, LGM, and PREIND simulations (Fig. 15). The amplitudes of the fluctuations are similar in LGMTOPO-PREIND and PREIND simulations and are

TABLE 2. The $e$-folding time scale (days) of the leading mode of variability of the NAO and the Northern Hemisphere AO for ERA-40 and the LGM and PREIND simulations.

\begin{tabular}{|c|c|c|c|c|c|c|c|c|c|}
\hline & \multirow[b]{2}{*}{ ERA-40 } & \multicolumn{2}{|c|}{ IPSL CM4 } & \multicolumn{2}{|c|}{ CNRM-CM3.3 } & \multicolumn{2}{|c|}{ MIROC3.2 } & \multicolumn{2}{|c|}{ HadCM3 } \\
\hline & & PREIND & LGM & PREIND & LGM & PREIND & LGM & PREIND & LGM \\
\hline $\mathrm{AO}$ & 14 & 11 & 9 & 9 & 12 & 10 & 7 & 15 & 17 \\
\hline NAO & 10 & 9 & 7 & 4 & 3 & 11 & 10 & 10 & 17 \\
\hline
\end{tabular}




\section{a. u composites at $500 \mathrm{hPa}$}

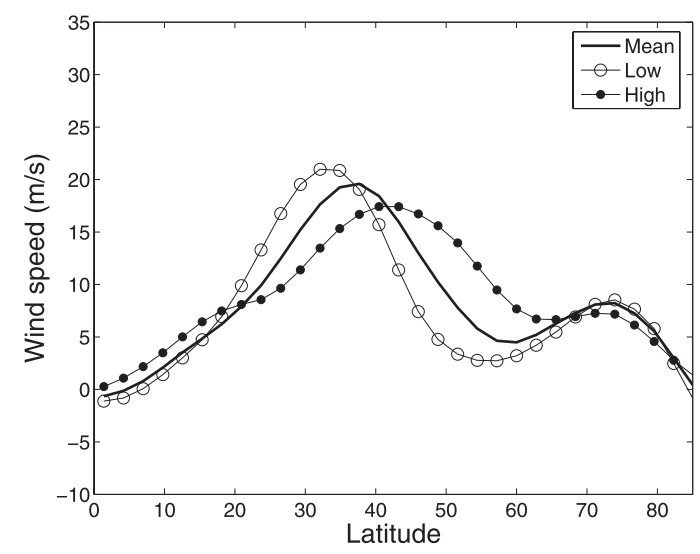

\section{b. High index}

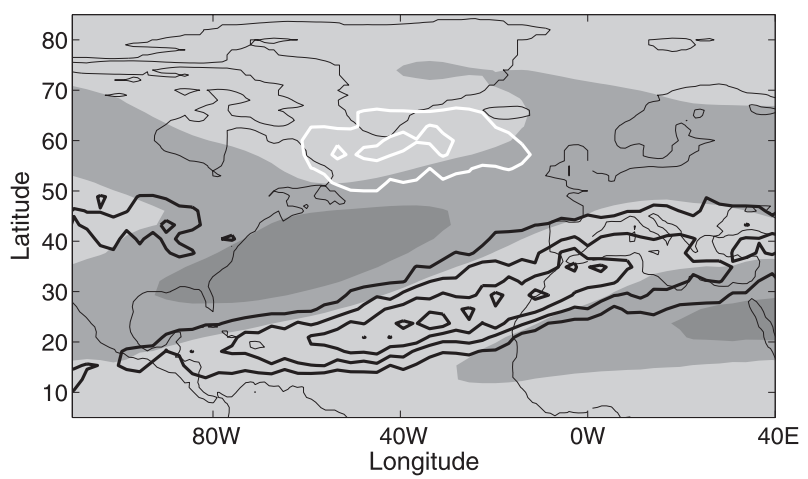

\section{c. Low index}

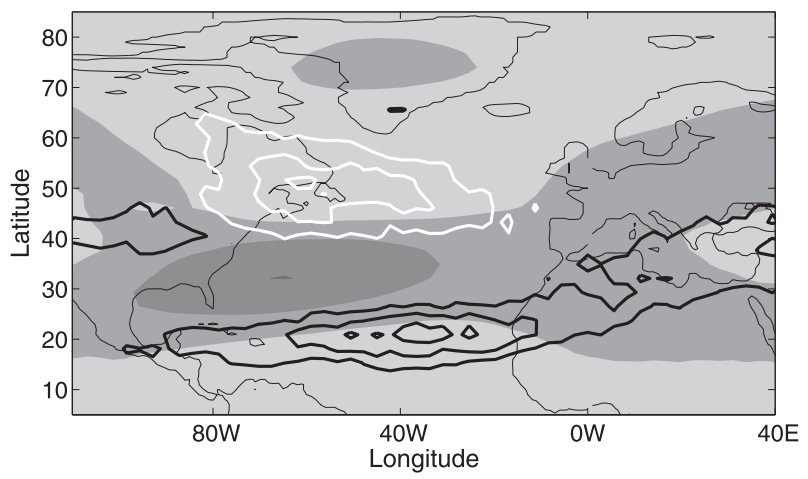

FIG. 14. As in Fig. 9, but for the simulation of CNRM-CM3.3 under LGM conditions except for the topography, which is that of the preindustrial climate.

stronger than those of LGM. The interpretation is the following: the high topography of the Laurentide Ice Sheet maintains very low temperatures in that region and the latitude of the low-level baroclinicity is fixed just to the southeast of the ice sheet. Because the fluctuations of the eddy-driven jet depends in large part on those of the more upstream low-level baroclinicity via the positive eddy feedback discussed previously, the presence of the

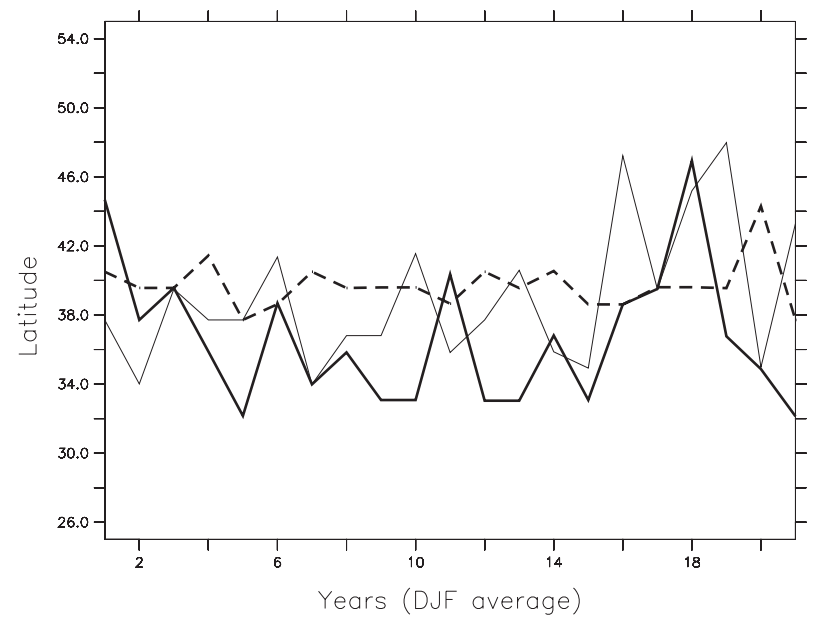

FIG. 15. Latitude of the maximum of the temperature gradient at $700 \mathrm{hPa}$, longitudinally averaged at the entrance of the Atlantic storm track $\left(80^{\circ}-60^{\circ} \mathrm{W}\right)$, as a function of the winter seasons, for CNRM-CM3.3. The LGM (thick dashed lines), PREIND (solid line), and LGM-TOPO-PREIND (thin solid line) simulations are shown.

topography prevents the latitudinal vacillation of the Atlantic jet.

\section{Conclusions}

This work aims at showing the usefulness of Rossby wave-breaking detection in the analysis of climate simulations and reanalysis data. It provides a new look at the interaction between the storm tracks and the timemean and low-frequency atmospheric circulations. A close link exists between the latitudinal fluctuations of the eddy-driven jets and the nature of the wave-breaking events: the higher (lower) the jet latitude, the more frequent the AWB (CWB) events. The two phenomena are interwoven and it is difficult to make the distinction between causes and effects. However, the reasoning is the following: climate simulations differing in their boundary conditions, such as their surface temperature, topography, or water vapor contents, create a systematic difference in the properties of the baroclinic waves during their growth. This difference makes the waves break more cyclonically or anticyclonically in one particular climate compared to the other when they reach their maximum amplitude at the end of the storm tracks. In turn, the cyclonic and anticyclonic preference will favor a more equatorward or poleward eddy-driven jet, respectively. This approach served as the leading axis of the present paper to better understand the difference between the LGM and preindustrial climates, but could also be used in the interpretation of future climate scenarios. 
First, the link between the latitudinal vacillation of the jets and the nature of the wave-breaking events has been confirmed in all of the datasets used in the present study. Second, the preindustrial simulations of the PMIP2 models when comparing with ERA-40 show a systematic deficit of AWB events in the Pacific and Atlantic, which may explain why the simulated general atmospheric circulation is more zonally oriented than the observed one. Indeed, one particular lack of the coupled models is the representation of the southwest-northeast tilt of the Atlantic jet and the occurrence of AWB events in the eastern side of the Atlantic domain.

The comparison between LGM and preindustrial PMIP2 simulations shows a global tendency toward more CWB and less AWB events in the LGM runs. This is systematically the case in the Pacific for the 4 models shown in the present study. In the Atlantic, the results are more complex: two models present a similar tendency to that in the Pacific (IPSL CM4 and HadCM3), one has no significant change (CNRM-CM3.3), and another has the reverse tendency (MIROC3.2). This change toward less AWB events, when it is significant, is accompanied by an equatorward shift of the eddy-driven jets on the eastern side of the storm tracks, which has been already emphasized by L09. Furthermore, wave-breaking events tend to always occur in the same regions in LGM runs while in the preindustrial climate they span a wider area.

The low-frequency variability in LGM exhibits much less latitudinal fluctuations of the eddy-driven jets than in PREIND. This result is systematically found for the two Northern Hemisphere storm tracks of the 4 models, and it is therefore very robust. Over the Atlantic, this can be viewed in terms of changes in the NAO; in the LGM, the latitudinal shift of the eddy-driven jet from one phase to another is much weaker. The positive phase has no more double-jet structure and presents a single jet extending more eastward than the negative phase. For some models, such as IPSL CM4 and CNRMCM3.3, the difference in latitude between the two phases is missing almost entirely and the NAO corresponds more to variations in the jet strength. To conclude, the present-day NAO is characterized by a wobbling of the Atlantic jet while the LGM NAO is characterized by its pulsing, to use the terminology of Vallis and Gerber (2008). This difference bears some resemblance with that between the Pacific and Atlantic eddy-driven jet of the actual climate. Indeed, as shown by Eichelberger and Hartmann (2007), during midwinter the Pacific jet presents more pulsing while the Atlantic jet presents more wobbling.

The previous result can be interpreted in terms of the temperature gradient, which is more fixed at a given latitude in LGM because of the presence of large and high ice sheets. The latitude of the temperature gradient has a strong influence on the nature of the wave breaking (see R09); the fact that it always stays more or less at the same latitude leads more systematically to the same type of breaking in the same regions. More precisely, the temperature gradient at the entrance of the storm tracks is not able to reach high latitudes, and therefore prevents the occurrence of AWB events. A simulation of CNRM-CM3.3 in which the topography of the ice sheet has been set to that of the present climate, but with all of the other characteristics of the LGM climate, presents many more latitudinal fluctuations of the eddy-driven jets than when the LGM topography is included. Thus, this particularity of the LGM climate essentially comes from the topography. Because the LGM wave-breaking events and atmospheric variability depend strongly on the ice sheet topography, our results on the LGM climate do not seem to be relevant to understand the common finding of poleward shift of midlatitude jets with global warming. Future studies will investigate more systematically the effect of the topography and the other LGM boundary conditions on synoptic eddy life cycles and upper-tropospheric wave-breaking processes.

Acknowledgments. The authors thank the PMIP2 international modeling groups for providing their data (http://pmip2.lsce.ipsl.fr), and participants of the Ensembles project that make possible the simulations of CNRMCM3. GR, AL, and GL acknowledge the support of ANR through contract ANR-JCJC-06-139163. GL is also supported by a grant from the MAIF foundation, and MK by the project ANR-BLANC IDEGLACE.

\section{REFERENCES}

Akahori, K., and S. Yoden, 1997: Zonal flow vacillation and bimodality of baroclinic eddy life cycles in a simple global circulation model. J. Atmos. Sci., 54, 2349-2361.

Benedict, J., S. Lee, and S. Feldstein, 2004: Synoptic view of the North Atlantic Oscillation. J. Atmos. Sci., 61, 121-144.

Braconnot, P., and Coauthors, 2007: Results of PMIP2 coupled simulations of the Mid-Holocene and Last Glacial MaximumPart 1: Experiments and large-scale features. Climate Past, 3, 261-277.

Chang, E., 2001: GCM and observational diagnoses of the seasonal and interannual variations of the Pacific storm track during the cool season. J. Atmos. Sci., 58, 1784-1800.

Donohoe, A., and D. S. Battisti, 2009: Causes of reduced North Atlantic storm activity in a CAM3 simulation of the Last Glacial Maximum. J. Climate, 22, 4793-4808.

Eichelberger, S., and D. Hartmann, 2007: Zonal jet structure and the leading mode of variability. J. Climate, 20, 5149-5163.

Feldstein, S., 2000: The time scale, power spectra, and climate noise properties of teleconnection patterns. J. Climate, 13, 44304440. 
Hoskins, B. J., I. N. James, and G. H. White, 1983: The shape, propagation and mean-flow interaction of large-scale weather systems. J. Atmos. Sci., 40, 1595-1612.

Joussaume, S., and K. Taylor, 1995: Status of the Paleoclimate Modeling Intercomparison Project (PMIP). Proc. First Int. AMIP Scientific Conf., Monterey, CA, WRCP, 425-430.

Justino, F., and W. R. Peltier, 2005: The glacial North Atlantic Oscillation. Geophys. Res. Lett., 32, L21803, doi:10.1029/ 2005 GL023822.

— and - 2008: Climate anomalies induced by the Arctic and Antarctic Oscillations: Glacial maximum and present-day perspectives. J. Climate, 21, 459-475.

— A. Timmermann, U. Merkel, and E. P. Souza, 2005: Synoptic reorganization of atmospheric flow during the Last Glacial Maximum. J. Climate, 18, 2826-2846.

- — — - - and W. R. Peltier, 2006: An initial intercomparison of atmospheric and oceanic climatology for the ICE-5G and ICE-4G models of LGM paleotopography. J. Climate, 19, 3-14.

Kageyama, M., and P. Valdes, 2000: Impact of the North American ice-sheet orography on the Last Glacial Maximum eddies and snowfall. Geophys. Res. Lett., 27, 1515-1518.

— regimes in past climate atmospheric general circulation model simulations. Climate Dyn., 15, 773-793.

—, P. Valdes, G. Ramstein, C. Hewitt, and U. Wyputta, 1999b: Northern Hemisphere storm tracks in present day and Last Glacial Maximum climate simulations: A comparison of the European PMIP models. J. Climate, 12, 742-760.

_ over the North Atlantic, Europe and western Siberia: A comparison between PMIP models, MARGO sea-surface temperatures and pollen-based reconstructions. Quat. Sci. Rev., 25, 2082-2102.

Keeley, S., R. T. Sutton, and L. C. Shaffrey, 2009: Does the North Atlantic Oscillation show unusual persistence on intraseasonal timescales? Geophys. Res. Lett., 36, L22706, doi:10.1029/ 2009GL040367.

Laîné, A., and Coauthors, 2009: Northern Hemisphere storm tracks during the Last Glacial Maximum in the PMIP2 ocean- atmosphere coupled models: Energetic study, seasonal cycle, precipitation. Climate Dyn., 32, 593-614.

Li, C., and D. S. Battisti, 2008: Reduced Atlantic storminess during Last Glacial Maximum: Evidence from a coupled climate model. J. Climate, 21, 3561-3579.

Martius, O., C. Schwierz, and H. Davies, 2007: Breaking waves at the tropopause in the wintertime Northern Hemisphere: Climatological analyses of the orientation and the theoretical LC1/2 classification. J. Atmos. Sci., 64, 2576-2592.

Nakamura, N., 1992: Midwinter suppression of baroclinic wave activity in the Pacific. J. Atmos. Sci., 49, 1629-1642.

Otto-Bliesner, B., E. C. Brady, G. Clauzet, R. Tomas, S. Levis, and Z. Kothavala, 2006: Last Glacial Maximum and Holocene climate in CCSM3. J. Climate, 19, 2526-2544.

Peltier, W., 1994: Ice age paleotopography. Science, 265, 195-201.

_ 2004: Global glacial isostasy and the surface of the ice-age Earth. Annu. Rev. Earth Planet. Sci., 32, 111-149.

Rivière, G., 2009: Effect of latitudinal variations in low-level baroclinicity on eddy life cycles and upper-tropospheric wavebreaking processes. J. Atmos. Sci., 66, 1569-1592.

_ track eddy activity and its relation with the North Atlantic Oscillation. J. Atmos. Sci., 64, 241-266.

Strong, C., and G. Magnusdottir, 2008: Tropospheric Rossby wave breaking and the NAO/NAM. J. Atmos. Sci., 65, 28612876.

Thompson, D. W. J., and J. M. Wallace, 2000: Annular modes in the extratropical circulation. Part I: Month-to-month variability. J. Climate, 13, 1000-1016.

Thorncroft, C. D., B. J. Hoskins, and M. McIntyre, 1993: Two paradigms of baroclinic-wave life-cycle behaviour. Quart. J. Roy. Meteor. Soc., 119, 17-55.

Uppala, S. M., and Coauthors, 2005: The ERA-40 Re-Analysis. Quart. J. Roy. Meteor. Soc., 131, 2961-3012.

Vallis, G., and E. Gerber, 2008: Local and hemispheric dynamics of the North Atlantic Oscillation, annular patterns and the zonal index. Dyn. Atmos. Oceans, 44, 184-212.

Woollings, T., B. Hoskins, M. Blackburn, and P. Berrisford, 2008: A new Rossby wave-breaking interpretation of the North Atlantic Oscillation. J. Atmos. Sci., 65, 609-626. 